\title{
Distributional and Efficiency Impacts of Clean and Renewable Energy Standards for Electricity
}

Sebastian Rausch and Matthew Mowers

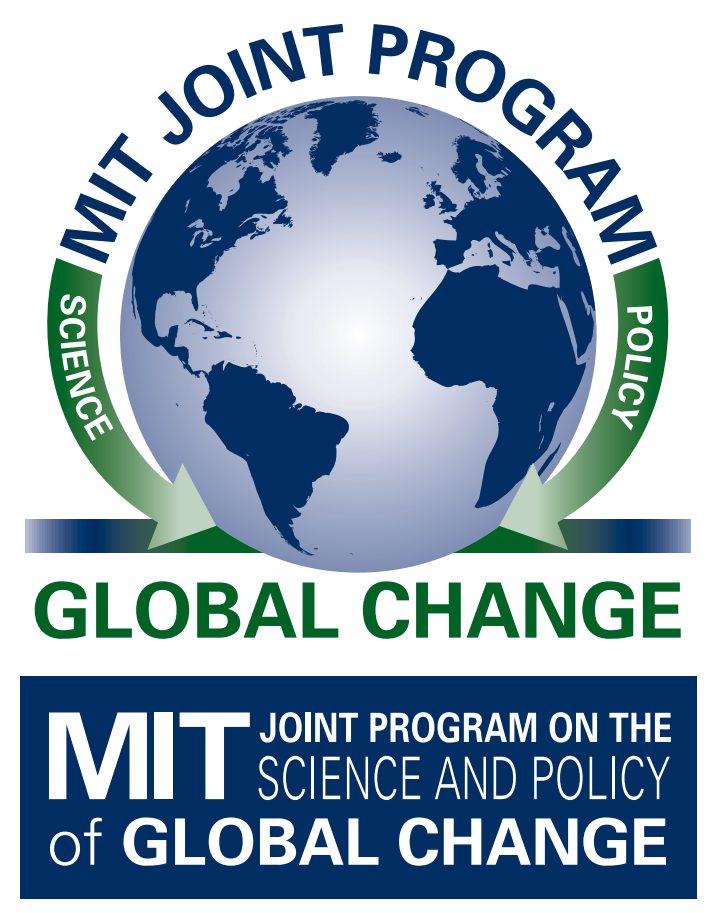

Report No. 225

July 2012 
The MIT Joint Program on the Science and Policy of Global Change is an organization for research, independent policy analysis, and public education in global environmental change. It seeks to provide leadership in understanding scientific, economic, and ecological aspects of this difficult issue, and combining them into policy assessments that serve the needs of ongoing national and international discussions. To this end, the Program brings together an interdisciplinary group from two established research centers at MIT: the Center for Global Change Science (CGCS) and the Center for Energy and Environmental Policy Research (CEEPR). These two centers bridge many key areas of the needed intellectual work, and additional essential areas are covered by other MIT departments, by collaboration with the Ecosystems Center of the Marine Biology Laboratory (MBL) at Woods Hole, and by short- and long-term visitors to the Program. The Program involves sponsorship and active participation by industry, government, and non-profit organizations.

To inform processes of policy development and implementation, climate change research needs to focus on improving the prediction of those variables that are most relevant to economic, social, and environmental effects. In turn, the greenhouse gas and atmospheric aerosol assumptions underlying climate analysis need to be related to the economic, technological, and political forces that drive emissions, and to the results of international agreements and mitigation. Further, assessments of possible societal and ecosystem impacts, and analysis of mitigation strategies, need to be based on realistic evaluation of the uncertainties of climate science.

This report is one of a series intended to communicate research results and improve public understanding of climate issues, thereby contributing to informed debate about the climate issue, the uncertainties, and the economic and social implications of policy alternatives. Titles in the Report Series to date are listed on the inside back cover.

Ronald G. Prinn and John M. Reilly

Program Co-Directors

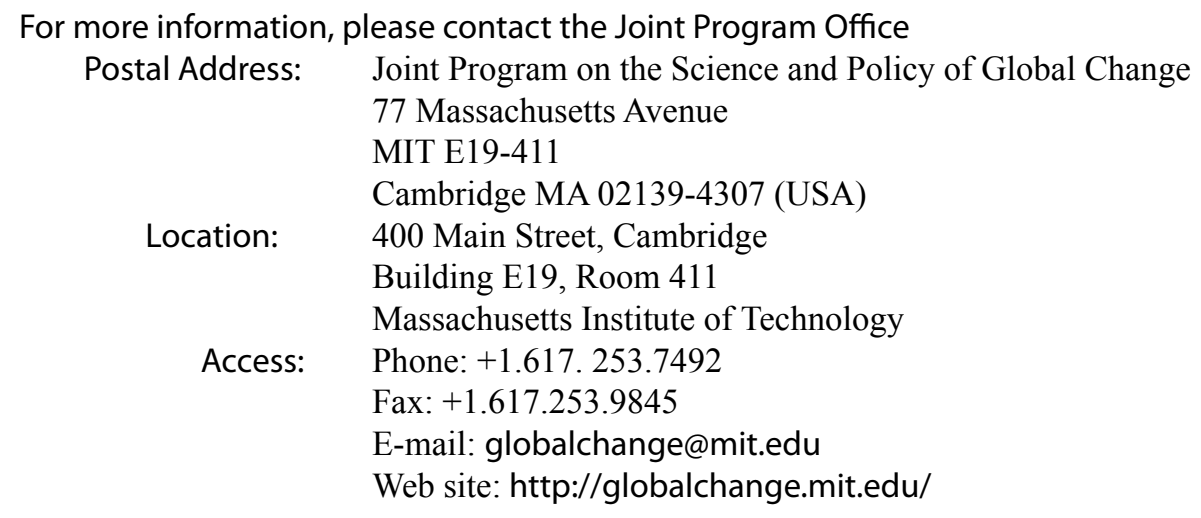

Printed on recycled paper 


\title{
Distributional and Efficiency Impacts of Clean and Renewable Energy Standards for Electricity
}

\author{
Sebastian Rausch* and Matthew Mowers ${ }^{\dagger}$
}

\begin{abstract}
We examine the efficiency and distributional impacts of greenhouse gas policies directed toward the electricity sector in a model that links a "top-down" general equilibrium representation of the U.S. economy with a "bottom-up" electricity-sector dispatch and capacity expansion model. Our modeling framework features a high spatial and temporal resolution of electricity supply and demand, including renewable energy resources and generating technologies, while representing $\mathrm{CO}_{2}$ abatement options in non-electric sectors as well as economy-wide interactions. We find that clean and renewable energy standards entail substantial efficiency costs compared to an economy-wide carbon pricing policy such as a cap-and-trade program or a carbon tax, and that these policies are regressive across the income distribution. The geographical distribution of cost is characterized by high burdens for regions that depend on non-qualifying generation fuels, primarily coal. Regions with abundant hydro power and wind resources, and a relatively clean generation mix in the absence of policy, are among the least impacted. An important shortcoming of energy standards vis-à-vis a first-best carbon pricing policy is that no revenue is generated that can be used to alter unintended distributional consequences.
\end{abstract}

\section{Contents}

1. INTRODUCTION 2

2. BACKGROUND ON CLEAN AND RENEWABLE ENERGY STANDARDS FOR ELECTRICITY 4

3. AN INTEGRATED ECONOMY-ENERGY-ELECTRICITY MODELING FRAMEWORK.. 6

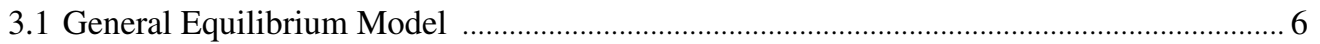

3.1 .1 Data

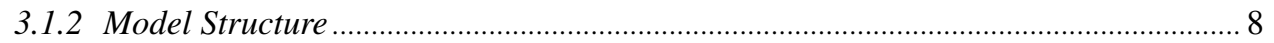

3.2 A Model of Electricity Generation and Transmission Capacity Expansion ......................... 14

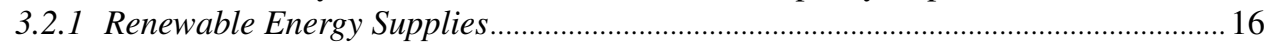

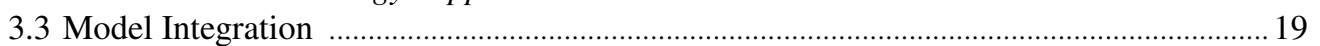

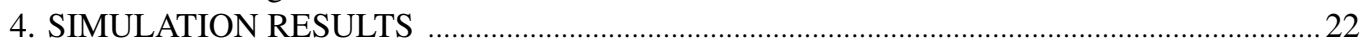

4.1 Scenarios and Assumptions Underlying the Simulation Dynamics ……………….............22

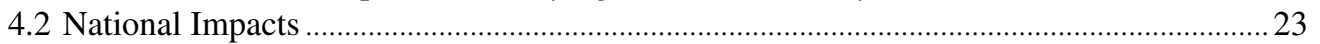

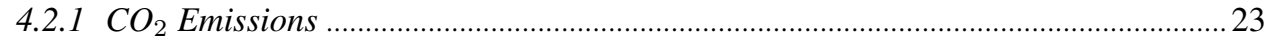

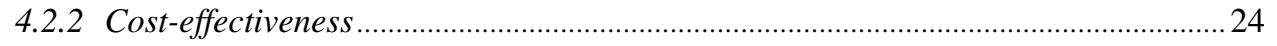

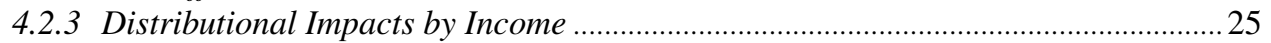

4.2.4 Electricity Price Impacts and Equilibrium Permit Prices ........................................26

4.2.5 Electricity Generation and Installed Generation Capacity ......................................22

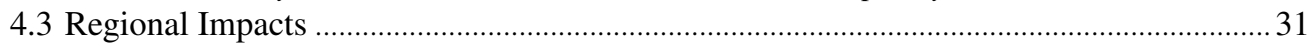

4.4 Comparison of Results with Other Studies.................................................................. 35

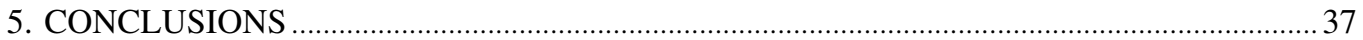

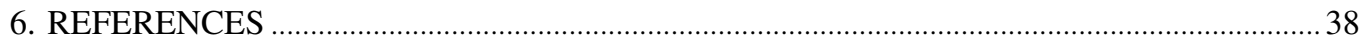

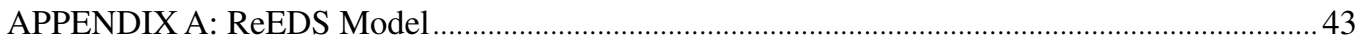

* Corresponding author. Email: rausch@mit.edu. Joint Program on the Science and Policy of Global Change, Massachusetts Institute of Technology, 77 Massachusetts Ave., Cambridge, MA 02139, U.S.

${ }^{\dagger}$ National Renewable Energy Laboratory, 1617 Cole Blvd., Golden, CO 80401-3305, U.S. 


\section{INTRODUCTION}

Following the failure in 2010 to pass a comprehensive cap-and-trade bill in the U.S., analysts and policymakers have called for new or more stringent policies to curb greenhouse gas (GHG) emissions in the electric power sector. In his 2011 State of the Union address, President Obama announced the goal of producing $80 \%$ of electricity from "clean" energy sources by 2035, and the 2011 Economic Report of the President indicates that a Clean Energy Standard (CES) is an important component of meeting the U.S. pledge, as part of the United Nations climate conferences in Copenhagen and Cancun, to reduce total $\mathrm{CO}_{2}$ emissions. The idea of a federal CES has been garnering bi-partisan support in Washington, D.C., and at latest count, thirty-six states (plus the District of Columbia) already employ renewable energy standards (RES) or CES programs, most of them mandating that 15 to $25 \%$ of total electricity production by 2020 has to come from renewable or "clean" sources (DSIRE, 2011). Energy standards in existing and proposed regulation differ with regard to the list of fuel sources included. Unlike a RES program, most CES proposals would credit not only renewable sources, like wind, solar, bio-power, hydropower and geothermal, but would also credit non-emitting non-renewable sources like nuclear energy, and would give partial crediting to certain other technologies, such as gas and coal technologies with carbon capture and storage (CCS), and natural gas combined cycle plants.

This paper examines the efficiency and distributional implications of RES and CES regulation in the U.S. electric power sector employing a numerical simulation model that is uniquely well-suited to assessing both economy-wide and electric sector impacts. We investigate the impacts of introducing a federal energy standard, formulated with and without a particular emphasis on incentivizing renewable energy, on economy-wide costs and emissions reductions, relating these impacts to changes in regional electricity generation and capacity (shifts to low carbon fuels and renewable sources), and changes in general equilibrium products and factor prices. We explore how the costs are distributed across households that differ by region and income. We compare the cost effectiveness and the distribution of impacts of such policies vis-à-vis a theoretical first-best permit market equilibrium (or a carbon tax) where marginal abatement costs across all sectors in the economy are equalized (see, e.g, Metcalf, 2009).

Several studies have examined how the U.S. electric sector responds to the imposition of a RES or CES. Besides assessments that evaluate performance of state-level RES programs based on past experiences (Langnissa and Wise, 2003; Wiser et al., 2007), some prior studies have employed simulation models to estimate impacts of federal RES/CES policies. A series of studies by the Energy Information Administration (Energy Information Administration, 2007, 2009a) uses the National Energy Modeling System (NEMS) (Energy Information Administration, 2009b) to examine a federal RES as specified under the American Clean Energy and Security Act and, more recently, a CES proposal that is closely related to the proposal by the Obama Administration (Energy Information Administration, 2011). Also based on the NEMS model, Palmer et al. (2010) and Palmer et al. (2011b) analyze a range of renewable and clean electricity standards aimed at promoting renewable and low-carbon sources of electricity. Palmer and Burtraw (2005) and Paul et al. (2011) use the Haiku model, a partial equilibrium model of the U.S. electricity sector, to 
compare the cost effectiveness of a federal RES and Renewable Energy Production Credit and to study the impacts of a federal CES on electricity prices and $\mathrm{CO}_{2}$ emissions. The National Energy Renewable Laboratory (NREL) analyzed the potential impacts of proposed national renewable electricity standard (RES) legislation using the Renewable Energy Deployment System (ReEDS) model, a linear programming generation, capacity expansion, and transmission model (Sullivan et al., 2009). Morris et al. (2010) employ a general equilibrium model with a top-down formulation of electricity to analyze impacts from combining a RES with a cap-and-trade policy.

The present study differs from earlier work in several ways. First, in contrast with all prior work $^{1}$, this analysis combines a general equilibrium (GE) model with a detailed bottom-up representation of the electric sector based on a decomposition algorithm (Böhringer and Rutherford, 2009) that exploits the block-diagonal structure of the Jacobian matrix of the problem. We fully integrate two existing large-scale simulation models, the MIT U.S. Regional Energy Policy (USREP) model (Rausch et al., 2010, 2011b), a recursive-dynamic multi-region GE model of the U.S. economy, and NREL's ReEDS (Renewable Energy Deployment System) model (Short et al., 2009), a recursive-dynamic linear programming model that simulates the least-cost expansion of electricity generation capacity and transmission, with detailed treatment of renewable electric options.

The key innovation of our approach is that electric-sector optimization is fully consistent with the equilibrium response of the economy including endogenously determined electricity demand, fuel prices, and goods and factor prices. Our integrated assessment allows us to provide theoretically sound welfare estimates, and enables us to assess the cost effectiveness of electricity standards vis-à-vis market-based carbon pricing policies by considering abatement opportunities in all sectors of the economy within a single consistent framework.

Our analysis is also germane to the literature on integrating "top-down" and "bottom-up" models for carbon policy assessment (see, for example, Hourcade et al., 2006, for an overview). Economy-wide "top-down" models represent sectoral economic activities and electric generation technologies through smooth, aggregate production functions. While the strength of these models is to include economy-wide interactions in an internally consistent framework, they typically lack detail along a number of important dimensions critical for analyzing electric sector impacts and, in particular, the potential of renewable energy sources. These include, among others, a exhaustive representation of all major renewable generation technologies, the characterization of renewable resources and electricity demand at sufficiently resolved spatial and temporal scales, capacity investment decisions including back-up for intermittent generation and storage, and access to and the cost of transmission using a spatially resolved representation of the grid. Our analysis is the first to embed a detailed electric sector model that includes all of these aspects in a

\footnotetext{
${ }^{1}$ Sugandha et al. (2009) also employ a hybrid top-down bottom-up modeling approach but their modeling framework has considerably less detail with respect to modeling important features of renewable electricity generation. Furthermore, their analysis does not consider the impacts of CES or RES policies in the electric sector.
} 
numerical general equilibrium framework. ${ }^{2}$ By doing so, we also overcome limitations inherent to partial equilibrium "bottom-up" electric sector models that typically rely on a simplistic Marshallian formulation of electricity demand (Lanz and Rausch, 2011) and fail to include interactions with the broader economic system.

A second major difference from earlier work is the model's ability to capture distributional effects. First, the economy-wide model distinguishes larger states and U.S. regions capturing inter-regional differences in carbon intensity of energy production, consumption, and trade. Second, within each region the model considers nine households differentiated by income levels. Households across income classes differ in terms of how income is derived from different sources and how income is spend across different commodities. This enables us to capture consumer impacts both on the uses and sources side of income. ${ }^{3}$ Sources side effects have been shown to be critical for assessing the incidence of environmental policies (Fullerton and Heutel, 2007; Rausch et al., 2011a), but the scope of a partial equilibrium electric-sector analysis implies that that those effects cannot be captured. Our integrated general equilibrium approach thus enables us to trace distributional impacts in several important dimensions.

The rest of the paper is organized as follows. Section 2 provides some background on CES and RES policies, with emphasis on the U.S. Section 3 outlines the model's data sources and structure. Section 4 presents and interprets results from policy simulations. Section 5 offers conclusions.

\section{BACKGROUND ON CLEAN AND RENEWABLE ENERGY STANDARDS FOR ELEC- TRICITY}

Under the typical design of an RES or CES, generators earn tradable certificates or credits for each unit of renewable or clean energy they produce. At the end of the accounting period, each firm must surrender RES/CES certificates equivalent to its required level of renewable/clean energy production, defined as a specified share of its total production.

An electricity standard with trading is closely related to the cap-and-trade approach to pollution control. Many state RES programs are intended as climate policies, and these can be thought of as $\mathrm{CO}_{2}$ cap-and-trade systems for the electric sector where the difference in carbon intensity among fuels is ignored. The disregard for differences in carbon content limits the cost effectiveness of the instrument. Cost effectiveness is also compromised because a RES/CES does not directly put a price on the externalities associated with fossil-based electricity generation; it

${ }^{2}$ In addition, a top-down representation of electricity markets implies that the price of electricity reflects the total carbon content of generation. This contrasts with real markets (and the bottom-up approach), where the carbon price is reflected in the electricity price through the carbon content of the marginal producer at a given point in time (Stavins, 2008).

${ }^{3}$ Environmental policies aimed at reducing carbon dioxide emissions will raise the price of carbon intensive commodities and disproportionately impact those households who spend larger than average shares of their income on these commodities. In a general equilibrium setting, environmental regulation also impacts factor prices. Households which rely heavily on income from factors whose factor prices fall relative to other factor prices will be adversely impacted. In the public finance literature on tax incidence, the first impact is referred to as a uses of income impact while the latter a sources of income impact (see, for example, Atkinson and Stiglitz, 1980, for a discussion of tax incidence). 
instead focuses on the ratio of renewable/clean- to fossil-based/"dirty" generation. Because of its focus on a ratio or input intensity, the RES/CES is equivalent to the combination of a subsidy to electricity production and tax on emissions. As shown by Holland et al. (2009), the subsidy component impedes cost effectiveness. In addition, a RES/CES program fails to exploit a broader range of behavioral responses to reduce $\mathrm{CO}_{2}$ emissions across all sectors of the economy. It may also not provide the same certainty for achieving a given emissions reductions target as an economy-wide cap-and-trade system due to potential leakage effects to non-electricity sectors.

RES programs have - since the late 1990s_-proliferated at the state level in the U.S. Until 2003, 14 states had enacted RES policies; at latest count, RES policies currently exist in 29 states and the District of Columbia; seven more states have non-binding goals. Existing RES programs apply to $47 \%$ of U.S. load in 2010. Most of the existing RES programs mandate that 15 to $25 \%$ of total electricity production by 2020 has to come from renewable sources. In general, the enactment of new RES policies is waning, but states continue to hone existing policies, with a general trend towards increased stringency of RES targets. ${ }^{4}$

At the federal level, a number of RES and CES proposals have been considered, but to date no proposal has been implemented. In the $111^{\text {th }}$ Congress, several electricity portfolio standards have been proposed including the House-passed H.R. 2454 American Clean Energy and Security Act of 2009 and three Senate bills: the American Clean Energy Leadership Act of 2009 (ACELA); the Practical Energy and Climate Plan Act (PECPA); and the Clean Energy Standard Act of (CESA). Both ACES and ACELA have a RES which would have required that, by 2020, 20\% and $30 \%$ of electricity generation come from renewable sources, respectively. The PECPA and CESA proposals include CES programs that provide credit for both renewable and lower-emitting, non-renewable energy sources comprising coal-CCS and new nuclear. Both proposals would mandate that $30 \%$ and $50 \%$ of electricity generation come from clean energy by 2030 and 2050, respectively. In addition, in his 2011 State of the Union address, President Obama expressed support for a CES that would require $80 \%$ of electricity generation to come from clean sources by 2035. Following the address, the White House released some general principles for a proposal for a CES, and more recently President Obama reiterated this call in a March 30, 2011 speech on energy policy. At the time of writing, it is unclear whether a federal CES or RES will come forward and how the exact parameters of such a policy would look like.

Other proposals include a CES that would be based on $\mathrm{CO}_{2}$ emissions intensity of power generation (Aldy, 2011). Such a technology-neutral approach would avoid picking winning technologies based on a policy decision on how to credit technologies under a portfolio approach, and promote a cost-effective allocation of emissions reductions within the power sector at a given point in time as the marginal cost of reducing $\mathrm{CO}_{2}$ are equated across different generators. ${ }^{5}$

\footnotetext{
${ }^{4}$ See DSIRE (2011), for an overview of existing RES policies. Wiser et al. (2007) provides an introduction to the history, concept, and design of the RES, and reviews early experience with the policy as applied at the state level.

${ }^{5}$ In principle, the CES approach could also be cost-effective in this regard, though this would require extensive credit trading provisions, allowing coal-intensive generators to exceed the standard by purchasing credits from other generators that are well below the standard (Parry and Williams III, 2011).
} 
Significantly, the federal programs would allow tradability of credits within the entire U.S., whereas most state policies contain significant statewide or regional limitations on renewable credit sources. A federal RES/CES program would therefore be at least as cost-effective as a combination of state-level programs.

\section{AN INTEGRATED ECONOMY-ENERGY-ELECTRICITY MODELING FRAMEWORK}

We formulate a recursive-dynamic general equilibrium (GE) model of the U.S. economy with a detailed bottom-up representation of electricity demand, generation, capacity expansion, and transmission. We embed NREL's ReEDS (Renewable Energy Deployment System) model (Short et al., 2009), a recursive-dynamic linear programming model that simulates the least-cost expansion of electricity generation capacity and transmission, with detailed treatment of renewable electric options, within the MIT USREP (U.S. Regional Energy Policy) model (Rausch et al., 2010, 2011b), a multi-region multi-commodity economy-energy GE model of the U.S. economy. We now turn to an overview of both sub-models and describe our approach to integrate them.

\subsection{General Equilibrium Model}

\subsubsection{Data}

This study makes use of a comprehensive energy-economy dataset that features a consistent representation of energy markets in physical units as well as detailed accounts of regional production and bilateral trade for the year 2004. The datset merges detailed state-level data for the U.S. with national economic and energy data for regions in the rest of the world and is outlined in detail by Caron and Rausch (2011). Social accounting matrices (SAM) in our hybrid dataset are based on data from the Global Trade Analysis Project (GTAP, 2008), the IMPLAN (IMpact analysis for PLANning) data (IMPLAN, 2008), and U.S. state-level accounts on energy balances and prices from the Energy Information Administration (2009c). Table 1 provides an overview of data sources.

The GTAP provides consistent global accounts of production, consumption, and bilateral trade as well as consistent accounts of physical energy flows and energy prices. Version 7 of the database, which is benchmarked to 2004, identifies 113 countries and regions and 57 commodities. The IMPLAN data specifies benchmark economic accounts for the 50 U.S. states (and the District of Columbia). The dataset includes input-output tables for each state that identify 509 commodities and existing taxes. The base year for the IMPLAN accounts in the version we use here is 2006 . To improve the characterization of energy markets in the IMPLAN data, we use least-square optimization techniques to merge IMPLAN data with data on physical energy quantities and energy prices from the Department of Energy's State Energy Data System (SEDS) for 2006 (Energy Information Administration, 2009c). ${ }^{6}$

\footnotetext{
${ }^{6}$ Aggregation and reconciliation of IMPLAN state-level economic accounts to generate a micro-consistent benchmark dataset which can be used for model calibration is accomplished using ancillary tools documented in Rausch and Rutherford (2009).
} 
Table 1. Data sources for USREP model.

\begin{tabular}{|c|c|}
\hline Data and parameters & Source \\
\hline \multicolumn{2}{|l|}{ Social accounting matrices bilateral trade } \\
\hline international regions & Global Trade Analysis Project (GTAP, 2008), Version 7 \\
\hline U.S. states & $\begin{array}{l}\text { IMPLAN (2008) and gravity analysis } \\
\text { (Lindall } \text { et al., 2006) }\end{array}$ \\
\hline U.S. state-to-country bilateral trade flows & $\begin{array}{l}\text { Origin of Movement and State of Destination data series } \\
\text { (U.S. Census Bureau, 2010) }\end{array}$ \\
\hline \multicolumn{2}{|l|}{ Physical energy flows and energy prices } \\
\hline international regions & GTAP (2008) \\
\hline U.S. states & State Energy Data System (Energy Information Administration, 2009c) \\
\hline Fossil fuel reserves & U.S. Geological Survey (US Geological Survey, 2009), \\
\hline and biomass supply & $\begin{array}{l}\text { U.S. Department of Energy (US Department of Energy, 2009), Dyni (2006) } \\
\text { Oakridge National Laboratories (2009) }\end{array}$ \\
\hline \multicolumn{2}{|l|}{ Population projections } \\
\hline international regions & United Nations $(2000,2001)$ \\
\hline U.S. states & U.S. Census Bureau (2000) \\
\hline Marginal personal income tax rates & NBER's TAXSIM model (Feenberg and Coutts, 1993) \\
\hline Trade elasticities & Global Trade Analysis Project (2008) and own calibration \\
\hline Energy demand and supply elasticities & Paltsev et al. (2005) \\
\hline
\end{tabular}

Data for trade flows between regions outside of the U.S. are taken from GTAP (2008) and reflect UN-COMTRADE bilateral flows. Bilateral state-to-state trade data in the IMPLAN database are derived using a gravity approach Lindall et al. (2006). ${ }^{7}$ Bilateral U.S. state-to-country trade flows are based on the U.S. Census Bureau Foreign Trade Statistics State Data Series (U.S. Census Bureau, 2010). Bilateral exports and imports are taken from, respectively, the Origin of Movement (OM) and State of Destination (SD) data series. The OM and SD data sets are available at the detailed 6-digit HS classification level, which permits aggregation to GTAP commodity categories.

We integrate GTAP, IMPLAN/SEDS, and U.S. Census trade data by using least-square optimization techniques. Our data reconciliation strategy is to hold fixed U.S. trade totals (by commodity) from GTAP and to minimize the distance between estimated and observed U.S. Census state-to-country bilateral trade flows and estimated and observed SAM data from IMPLAN subject to equilibrium constraints.

For this study, we aggregate the dataset to 12 U.S. regions, 2 regions in the rest of the world (Europe and the "Rest of the World"), 10 commodity groups, and 9 households grouped by annual income classes (see Table 2). States identified in the model include California, Texas,

\footnotetext{
${ }^{7}$ The IMPLAN Trade Flows Model draws on three data sources: the Oak Ridge National Labs county-to-county distances by mode of transportation database, the Commodity Flows Survey (CFS) ton-miles data by commodity, and IMPLAN commodity supply and demand estimates by county.
} 


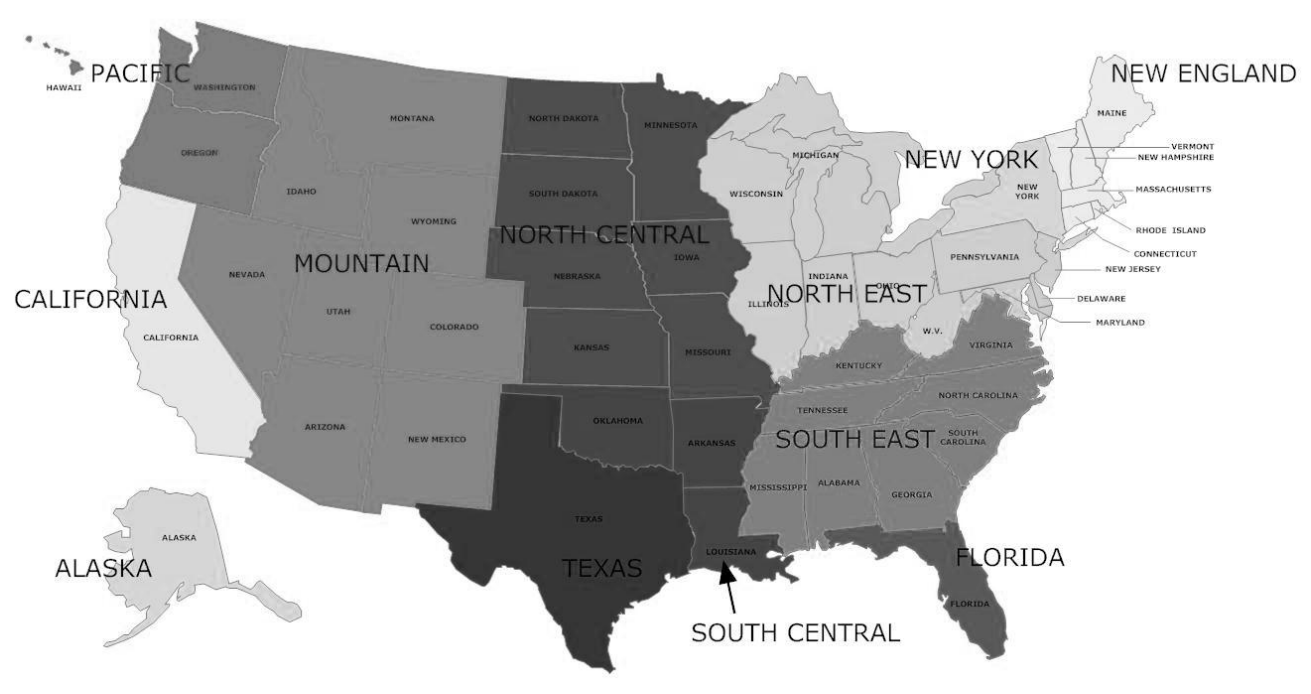

Figure 1. U.S. regions in USREP model.

Florida, and New York, and several other multi-state regional composites. Mapping of states to aggregated regions is shown in Figure 1. Our commodity aggregation identifies five energy sectors and five non-energy composites. Energy commodities identified in our study include coal (COL), natural gas (GAS), crude oil (CRU), refined oil (OIL), and electricity (ELE), which allows to distinguish energy goods and specify substitutability between fuels in energy demand. Elsewhere, we distinguish energy-intensive products (EIS), other manufacturing (OTH), agriculture (AGR), transportation (TRN), and services (SRV). Primary factors in the dataset include labor, capital, land, and fossil-fuel resources.

Energy supply is regionalized by incorporating data for regional crude oil and natural gas reserves (US Department of Energy, 2009), coal reserves U.S. Geological Survey (US Geological Survey, 2009), and shale oil (Dyni, 2006). We derive regional supply curves for biomass from data from Oakridge National Laboratories (2009) that describes quantity and price pairs for biomass supply for each state.

Our dataset permits calculation of existing taxes rates comprising sector- and region-specific ad valorem output taxes, payroll taxes and capital income taxes. IMPLAN data has been augmented by incorporating regional tax data from the NBER TAXSIM model (Feenberg and Coutts, 1993) to represent marginal personal income tax rates by region and income class.

\subsubsection{Model Structure}

Production and transformation technologies. In each industry $(i=1, \ldots, J)$ and region $(r=1, \ldots, R)$ gross output $Y_{i r}$ is produced using inputs of labor $\left(L_{i r}\right)$, capital $\left(K_{i r}\right)$, natural resources including coal, natural gas, crude oil, and land $\left(R_{i r}\right)$, and produced intermediate inputs 
Table 2. USREP model details.

\begin{tabular}{lll}
\hline Sectors & Regions & Primary production factors \\
\hline Non-Energy & Pacific (PACIF) & Capital \\
Agriculture (AGR) & California (CA) & Labor \\
Services (SRV) & Alaska (AK) & Coal resources \\
Energy-intensive products (EIS) & Mountain (MOUNT) & Natural gas resources \\
Other industries products (OTH) & North Central (NCENT) & Crude oil resources \\
Commercial Transportation (TRN) & Texas (TX) & Hydro resources \\
Passenger vehicle transportation (TRN) & South Central (SCENT) & Nuclear resources \\
Final demand sectors & North East (NEAS) & Land \\
Household demand & South East (SEAST) & \\
Government demand & Florida (FL) & Household income classes \\
Investment demand & New York (NY) & $(\$ 1,000$ of annual income) \\
\cline { 2 - 3 } Energy supply and conversion & New England (NENGL) & $<10$ \\
Fuels production & & $10-15$ \\
Coal (COL) & Europe (EUR) & $15-25$ \\
Natural gas (GAS) & Rest of the World (ROW) & $25-30$ \\
Crude oil (CRU) & & $30-50$ \\
Refined oil (OIL) & & $50-75$ \\
Electricity generation and transmission & & $75-100$ \\
as represented by ReEDS model (see Section ) & $100-150$ \\
& & $>150$ \\
\hline
\end{tabular}

$$
\begin{aligned}
X_{j i r}, j & =i{ }^{8} \\
Y_{i r} & =F_{i r}\left(L_{i r}, K_{i r}, R_{i r} ; X_{1 i r}, \ldots, X_{I i r}\right) .
\end{aligned}
$$

We employ constant-elasticity-of-substitution (CES) functions to characterize the production systems and distinguish four types of production activities in the model: fossil fuels (indexed by $f=\{\mathrm{CRU}, \mathrm{COL}, \mathrm{GAS}\}$ ), refined oil (OIL), agriculture (AGR), and non-energy industries (indexed by $n=\{$ TRN,EIS,SRV,OTH $\}$ ). All industries are characterized by constant returns to scale (except for fossil fuels and AGR which are produced subject to decreasing returns to scale) and are traded in perfectly competitive markets. Nesting structure for each type of production system are depicted in Paltsev et al. (2005).

Hence, fossil fuel $f$, for example, is produced according to a nested CES function combining a fuel-specific resource, capital, labor, and intermediate inputs:

$$
Y_{f r}=\left[\alpha_{f r} R_{f r}^{\rho_{f r}^{R}}+\nu_{f r} \min \left(X_{1 f r}, \ldots, X_{I f r}, V_{f r}\right)^{\rho_{f r}^{R}}\right]^{1 / \rho_{f r}^{R}}
$$

where $\alpha, \nu$ are share coefficients of the CES function and $\sigma_{f r}^{R}=1 /\left(1-\rho_{f r}^{R}\right)$ is the elasticity of substitution between the resource and the primary-factors/materials composite. The primary

\footnotetext{
${ }^{8}$ For ease of exposition, we abstract from the various tax rates that are used in the model.
} 
factor composite is a Cobb-Douglas of labor and capital: $V_{f r}=L_{f r}^{\beta_{f r}} K_{f r}^{1-\beta_{f r}}$ where $\beta$ is the labor share.

We adopt a putty-clay approach where a fraction $\phi$ of previously-installed capital becomes non-malleable and frozen into the prevailing techniques of production. The fraction $1-\phi$ can be thought of as that proportion of previously-installed malleable capital that is able to have its input proportions adjust to new input prices. Vintaged production in industry $i$ that uses non-malleable capital is subject to a fixed-coefficient transformation process in which the quantity shares of capital, labor, intermediate inputs and energy by fuel type are set to be identical to those in the base year:

$$
Y_{i r}^{v}=\min \left(L_{i r}^{v}, K_{i r}^{v}, R_{i r}^{v} ; X_{1 i r}^{v}, \ldots, X_{\text {Iir }}^{v}\right)
$$

In each region, a single government entity approximates government activities at all levels-federal, state, and local. Aggregate government consumption is represented by a Leontief composite: $G_{r}=\min \left(G_{1 r}, \ldots, G_{i r}, \ldots, G_{I r}\right)$.

Consumer preferences. In each region $r$, preferences of the representative consumers for income class $h$ are represented by a CES utility function of consumption goods $\left(C_{i}\right)$, investment $(I)$, and leisure $(N)$ :

$$
U_{r, h}=\left[\mu_{c r}^{h} \min \left[g^{h}\left(C_{1 r h}, \ldots, C_{I r h}\right), \min \left(I_{1 r h}, \ldots, I_{I r h}\right)\right]^{1 / \rho_{c r}}+\gamma_{c r}^{h} N_{r h}^{1 / \rho_{c r}}\right]^{1 / \rho_{c r}}
$$

where $\mu$ and $\gamma$ are CES share coefficients, and the elasticity of substitution between leisure and the consumption-investment composite is given by $\sigma_{l, r}=1 /\left(1-\rho_{c r}\right) \cdot g(\cdot)$ is a CES composite of energy and non-energy goods whose nesting structure is depicted in Paltsev et al. (2005) Thus, our framework captures heterogeneity in private consumption with respect to region and income. Households differ by expenditure patterns and income sources.

Supplies of final goods and intra-U.S. and international trade. With the exception of crude oil, which is a homogeneous good, intermediate and final consumption goods are differentiated following the Armington (1969) assumption. For each demand class, the total supply of good $i$ is a CES composite of a domestically produced (i.e., locally produced and imported from domestic markets) variety and an imported (from foreign markets) one:

$$
\begin{aligned}
& X_{i r}=\left[\psi^{z} Z D_{i r}^{\rho_{i}^{D}}+\xi^{z} Z M_{i r}^{\rho_{i}^{D}}\right]^{1 / \rho^{D}{ }_{i}} \\
& C_{i r h}=\left[\psi^{c} C D_{i r h}^{\rho_{i}^{D}}+\xi^{c} C M_{i r h}^{\rho_{i}^{D}}\right]^{1 / \rho^{D_{i}}} \\
& I_{i r h}=\left[\psi^{i} I D_{i r h}^{\rho_{i}^{D}}+\xi^{i} I M_{i r h}^{\rho_{i}^{D}}\right]^{1 / \rho^{D}{ }_{i}}
\end{aligned}
$$




$$
G_{i r}=\left[\psi^{g} G D_{i r}^{\rho_{i}^{D}}+\xi^{g} G M_{i r}^{\rho_{i}^{D}}\right]^{1 / \rho^{D_{i}}}
$$

where $Z, C, I$, and $G$ are inter-industry demand, consumer demand, investment demand, and government demand of good $i$, respectively, and where $Z D, C D, I D$, and $G D$, are domestic and imported components of each demand class, respectively. The $\psi$ 's and $\xi$ 's are the CES share coefficients and the Armington substitution elasticity between the domestic and the imported foreign variety in these composites is $\sigma_{i}^{D}=1 /\left(1-\rho_{i}^{D}\right)$.

The domestic imported varieties are represented by nested CES functions, and we differentiate the following structure for U.S. regions (indexed by $s=1, \ldots, S$ ) and international regions (indexed by $t=1, \ldots, T$ ). The imported variety of good $i$ is represented by the CES aggregate:

$$
M_{i r}= \begin{cases}{\left[\left(\sum_{s} \pi_{i s t} y_{i s r}^{\rho_{i}^{R U}}\right)^{\rho_{i}^{M} / \rho_{i}^{R U}}+\sum_{t \neq r} \varphi_{i t r} y_{i t r}^{\rho_{i}^{M}}\right]^{1 / \rho_{i}^{M}}} & \text { if } r=t \\ {\left[\sum_{t} \varphi_{i t r} y_{i t r}^{\rho_{i}^{M}}\right]^{1 / \rho_{i}^{M}}} & \text { if } r=s\end{cases}
$$

where $y_{i t r}\left(y_{i s r}\right)$ are imports of commodity $i$ from region $t(s)$ to $r . \pi$ and $\varphi$ are the CES share coefficients, and $\sigma_{i}^{M}=1 /\left(1-\rho_{i}^{M}\right)$ and $\sigma_{i}^{R U}=1 /\left(1-\rho_{i}^{R U}\right)$ are the implied substitution elasticity across foreign and intra-U.S. origins, respectively. The domestic variety of good $i$ for U.S. region $s$ is represented by the CES aggregate:

$$
D_{i r}= \begin{cases}{\left[\left(\sum_{s \neq r} \pi_{i s r} y_{i s r}^{\rho_{i}^{S U}}\right)^{\rho^{D U_{i}} / \rho_{i}^{S U}}+\eta_{i r} y_{i}^{\rho_{i r}^{D U}}\right]^{1 / \rho_{i}^{D U}}} & \text { if } r=s \\ y_{i r} & \text { if } r=t\end{cases}
$$

where $\eta$ is a CES share coefficient, and $\sigma_{i}^{D U}=1 /\left(1-\rho_{i}^{D U}\right)$ is the implied substitution elasticities between the local variety and a CES composite of intra-U.S. varieties. $\sigma_{i}^{S U}=1 /\left(1-\rho_{i}^{S U}\right)$ is the elasticity of substitution across U.S. origins.

Intra-period equilibrium and model closure. Consumption, labor supply, and savings result from the decisions of the representative household in each region maximizing its utility subject to a budget constraint that full consumption equals income:

$$
\max _{\left\{C_{i r h}, I_{r h}, N_{r h}\right\}} U_{r h} \text { s.t. } p_{r}^{i} I_{r h}+p_{r}^{l} N_{r h}+\sum_{i} p_{i r}^{c} C_{i r h}=p_{r}^{k} \bar{K}_{r h}+p_{r}^{V k} \overline{V K}_{r h}+p_{f r}^{R} \bar{R}_{f r h}+p_{r}^{l} \bar{L}_{r h}+T_{r h}
$$

where $p^{i}, p^{c}, p^{k}, p^{V k}, p^{R}$, and $p^{l}$, are price indices for investment, labor services, household consumption (gross of taxes), capital services, rents on vintaged capital, and rents of fossil fuel resources, respectively. $\bar{K}, \overline{V K}, \bar{R}, \bar{L}$, and $T$ are the benchmark stocks of capital, vintaged capital, fossil fuel resources, labor, and the benchmark transfer income, respectively. Lacking 
specific data on capital ownership, households are assumed to own a pool of U.S. capital-that is they do not disproportionately own capital assets within the region in which they reside.

Fossil fuel resources and vintaged capital are treated as sector-specific, whereas capital for international regions and labor for international and U.S. regions are treated as perfectly mobile across sectors within a given region but immobile across regions. Capital in the U.S. is assumed to be perfectly mobile across U.S. regions but immobile across international regions. Except for labor, all factors are inelastically supplied.

Given input prices gross of taxes, firms maximize profits subject to the technology constraints in Eqs. (1) and (3). Minimizing input costs for a unit value of output yields a unit cost indexes (marginal cost), $p_{i r}^{Y}$ and $p_{i r}^{Y v}$. Firms operate in perfectly competitive markets and maximize their profit by selling their products at a price equal to these marginal costs.

The main activities of the government sector in each region are purchasing goods and services, transferring incomes, and raising revenues through taxes. Government income is given by: $G O V_{r}=T A X_{r}-\sum_{h} T_{r, h}-B_{r}$, where $T A X, T_{r, h}$, and $B$ are tax revenue, transfer payments to households and the initial balance of payments (deficit), respectively. Aggregate demand by the government is given by: $G D_{r}=G O V_{r} / p_{r}^{G}$ where $p_{r}^{G}$ is the price for aggregate government consumption.

Market clearance equations for factors that are supplied inelastically are trivial. The other market clearance equations are as follow:

1. Supplies to the domestic market must meet demands by industry, household, investment, and government: $D_{i r}=Z D_{i r}+\sum_{h}\left(C D_{i r h}+I D_{i r h}\right)+G D_{i r}$.

2. Import supply of good $i$ satisfies domestic demands by industry, household, investment, and government for the imported variety:

$$
M_{i r}=Z M_{i r}+\sum_{h}\left(C M_{i r h}+I M_{i r h}\right)+G M_{i r} .
$$

3. Trade between all regions in each commodity has to balance:

$$
\sum_{s} \sum_{r} y_{i s r}+\sum_{t} \sum_{r} y_{i t r}=\sum_{s} \sum_{r} y_{i r s}+\sum_{t} \sum_{r} y_{i r t} \text {. }
$$

4. Labor supply has to equal labor demand.

Intertemporal dynamics. We adopt a recursive-dynamic approach in which economic agents have myopic expectations and base their decisions on contemporaneous variables. Solving the dynamic model therefore involves computing a sequence of equilibria from the intra-period model.

The evolution of capital over time is governed by the following set of dynamic equations. Malleable capital $\left(K^{m}\right)$ in period $t$ is made up of investment $\left(I_{t}\right)$, plus the stock of capital remaining after depreciation that also remains malleable:

$$
K_{t+1}^{m}=I_{t}+(1-\phi)(1-\delta) K_{t}^{m}
$$

where $\delta$ and $\phi$ denote the depreciate rate and the fraction of previously-installed malleable capital that become non-malleable, respectively. Malleable capital is indistinguishable from new 
investment, in that there is flexibility defined by the nested CES production function to adjust the input proportions given prevailing relative prices. As the model steps forward in time it preserves $v=1, \ldots, 12$ vintages of rigid capital $\left(K^{r}\right)$, each retaining the coefficients of factor demand fixed at the levels that prevailed when it was installed. ${ }^{9}$ Each of the sector specific vintages is tracked through time as a separate capital stock. In period $t+1$, the first vintage of non-malleable capital is given by:

$$
K_{i, t+1, v}^{r}=\phi(1-\delta) K_{i, t}^{m} \quad \text { for } v=1 .
$$

We assume that rigid capital cannot be reallocated among different sectors. In each sector, the quantity of capital in each of the remaining vintages is thus simply the amount of each vintage that remains after depreciation:

$$
K_{i, t+1, v+1}^{r}=(1-\delta) K_{i, t, v}^{r} \quad \text { for } v=2, \ldots, 10 .
$$

This formulation means that the model exhibits a short-run and long-run response to changes in relative prices. The substitution response in a single period to a change in prices in that periods is a combination of the long-run substitution possibilities, weighted by output produced by malleable capital, and no substitution, weighted by output produced with vintaged capital.

Over time, energy resources $R$ in sector $i$ are subject to depletion based on physical production of fuel $(F)$ in the previous period:

$$
R_{r, i, t+1}=R_{r, i, t}-F_{r, i, t}
$$

Elasticities, calibration, and model solution. As customary in applied general equilibrium analysis, we use prices and quantities of the integrated economic-energy dataset for the base year to calibrate the value share and level parameters in the model. Exogenous elasticities determine the free parameters of the functional forms that capture production technologies and consumer preferences. Reference values for elasticity parameters are taken from Paltsev et al. (2005) and are shown in Table 3. Values for Armington trade elasticities are based on econometric estimates from GTAP (2008).

All fossil energy resources are modeled as graded resources whose cost of production rises continuously as they are depleted. The resource grade structure is reflected by the elasticity of substitution between resources and the capital-labor-materials bundle in the production function. Given the form of the production function in Eq. (2), the elasticity of substitution between the resource and the other inputs in the top nest determines the price elasticity of supply $\left(\zeta_{f}\right)$ at the reference point according to:

$$
\zeta_{f}=\sigma_{f r}^{R} \frac{1-\alpha_{f r}}{\alpha_{f r}}
$$

${ }^{9}$ Because there are 12 vintages and the model's time step is two years, vintaged capital has a maximum life of 24 years. 
Population and labor productivity growth over time are exogenous. Labor in efficiency units $\left(L_{r, t}\right)$ is scaled from its base-year value $\left(\bar{L}_{r}\right)$ according to: $L_{r, t+1}=\bar{L}_{r}\left(1+\gamma_{r, t}\right)$ where the exogenous augmentation rate $\gamma_{r, t}=\gamma_{r, t}^{L}+\gamma_{r, t}^{P}$ comprises the growth of population $\left(\gamma_{r, t}^{L}\right)$ and the growth of productivity $\left(\gamma_{r, t}^{P}\right) \cdot \gamma_{r, t}^{L}$ is specified using population projections from United Nations (2001) and U.S. Census Bureau (2000) for international and U.S. regions, respectively. Labor productivity growth over time is described by a logistic function:

$\gamma_{r, t}^{P}=\left(\gamma_{r, 0}^{P}-\gamma_{r, T}^{P}\right) \frac{1+\alpha}{1+\alpha^{\beta t}}+\gamma_{r, T}^{P}$. The value of the logistic parameters $\alpha$ and $\beta$ are set such that productivity adjusts from the initial rate to the final rate in year 2100 in an S-shaped fashion. Growth for historical years is overridden by specifying an augmentation factor so that simulated GDP growth matches observed historical rates over these periods.

The labor supply response within a given period is determined by the household choice between leisure and labor. We calibrate compensated and uncompensated labor supply elasticities following the approach described in Ballard (2000), and assume that the uncompensated (compensated) labor supply elasticity is $0.05(0.3)$.

Non-price induced efficiency improvements in energy demand that scale production and consumption sectors' use of energy per unit of output are modeled following the concept of autonomous energy efficiency improvements (AEEI) (see, e.g., Paltsev et al., 2005). We assume for all regions that AEEI occur at a rate of $1 \%$ per year.

Numerically, the equilibrium is formulated as a mixed complementarity problem (Mathiesen, 1985; Rutherford, 1995). Our complementarity-based solution approach comprises two classes of equilibrium conditions: zero profit and market clearance conditions. The former condition determines a vector of activity levels and the latter determines a vector of prices. We formulate the problem in GAMS and use the mathematical programming system MPSGE (Rutherford, 1999) and the PATH solver (Dirkse and Ferris, 1995) to solve for non-negative prices and quantities.

\subsection{A Model of Electricity Generation and Transmission Capacity Expansion}

The electric sector sub-model is based on the ReEDS model (Short et al., 2009), a linear programming model developed by the U.S. Department of Energy's National Renewable Energy Laboratory that simulates the least-cost expansion of electricity generation capacity and transmission in the contiguous U.S. ReEDS provides a means of estimating the type and location of conventional and renewable resource development, the transmission infrastructure expansion requirements of those installations, the composition and location of generation, storage, and demand-side technologies needed to maintain system reliability. ReEDS provides a detailed treatment of electricity-generating and electrical storage technologies, and specifically addresses a variety of issues related to renewable energy technologies, including accessibility and cost of transmission, regional quality of renewable resources, seasonal and diurnal generation profiles, variability and non-dispatchability of wind and solar power, and the influence of variability on curtailment of those resources. ReEDS addresses these issues through a highly discretized regional structure, temporal resolution, explicit statistical treatment of the variability in wind and solar output over time, and consideration of ancillary services requirements and costs. 
Table 3. Reference values of substitution elasticities in production, consumption, and trade.

\begin{tabular}{|c|c|c|}
\hline Parameter & Substitution margin & Value \\
\hline$\sigma_{e n}$ & Energy & 1.0 \\
\hline$\sigma_{\text {enoe }}$ & Energy-electricity & 0.5 \\
\hline$\sigma_{\text {eva }}$ & Energy/electricity-value-added & 0.5 \\
\hline$\sigma_{v a}$ & Capital—labor & 1.0 \\
\hline$\sigma_{\text {klem }}$ & Capital/labor/energy—materials & 0 \\
\hline$\sigma_{a m}$ & Materials in AGR & 0 \\
\hline$\sigma_{a e}$ & Energy/electricity-materials in AGR & 0.3 \\
\hline$\sigma_{e r}$ & Energy/materials_-land in AGR & 0.6 \\
\hline$\sigma_{\text {erva }}$ & Energy/materials/land—value-added in AGR & 0.7 \\
\hline$\sigma_{r k l m}$ & Capital/labor/materials_-resource in primary energy & 0 \\
\hline$\sigma_{g r}$ & Capital/labor/materials-resources & Calibrated \\
\hline$\sigma_{\text {govinv }}$ & Materials-energy in government and investment demand & 0.5 \\
\hline$\sigma_{c t}$ & Transportation-Non-transport in private consumption & 1.0 \\
\hline$\sigma_{e c}$ & Energy-Non-energy in private consumption & 0.25 \\
\hline$\sigma_{c}$ & Non-energy in private consumption & 0.25 \\
\hline$\sigma_{e f}$ & Energy in private consumption & 0.4 \\
\hline$\sigma_{l}$ & Leisure-material consumption/investment & Calibrated \\
\hline$\sigma_{i}^{D}$ & Foreign-domestic (and local) & Based on GTAP, version 7 \\
\hline$\sigma_{i}^{M}$ & Across foreign origins & Based on GTAP, version 7 \\
\hline$\sigma_{i}^{R U}$ & Across U.S. origins for international regions & $2 \sigma_{i}^{M}$ \\
\hline$\sigma_{i}^{D U}$ & Local—domestic for U.S. regions & $2 \sigma_{i}^{D}$ \\
\hline$\sigma_{i}^{S U}$ & Across U.S. origins for U.S. regions & $2 \sigma_{i s}^{D U}$ \\
\hline
\end{tabular}

Note: Substitution elasticity for fossil fuel, nuclear, and hydro resource factors are calibrated according to Eq. (16) using the following estimates for price elasticities of supply: zet $a_{\mathrm{COL}}=\zeta_{\mathrm{GAS}}=1$, and

$\zeta_{\mathrm{CRU}}=0.5 . \sigma_{l}$ is calibrated assuming that the compensated and uncompensated labor supply elasticity is 0.05 and 0.3 , respectively.

Table 4 provides a list of generation and storage technologies considered in the ReEDS model. ReEDS includes all major generator types and has additional detail for renewable generators as these generators come with concerns that many conventional dispatchable power plants do not have, including variations in regional resource quality, variability and non-dispatchability, and additional transmission needs. Time in ReEDS is subdivided within each two-year period, with each year divided into four seasons with a representative day for each season, which is further divided into four diurnal time-slices. Also, there is one additional summer-peak time-slice. These 17 annual time-slices enable ReEDS to capture the intricacies of meeting electric loads that vary throughout the day and year-with both dispatchable and non-dispatchable generators. See Table A3 for a definition of time slices.

The major constraints in the optimization include meeting electricity demand and reserve requirements within specific regions, regional resource supply limitations, and transmission constraints. The capacity expansion and dispatch decision-making of ReEDS considers the net 
Table 4. Generation and storage technologies.

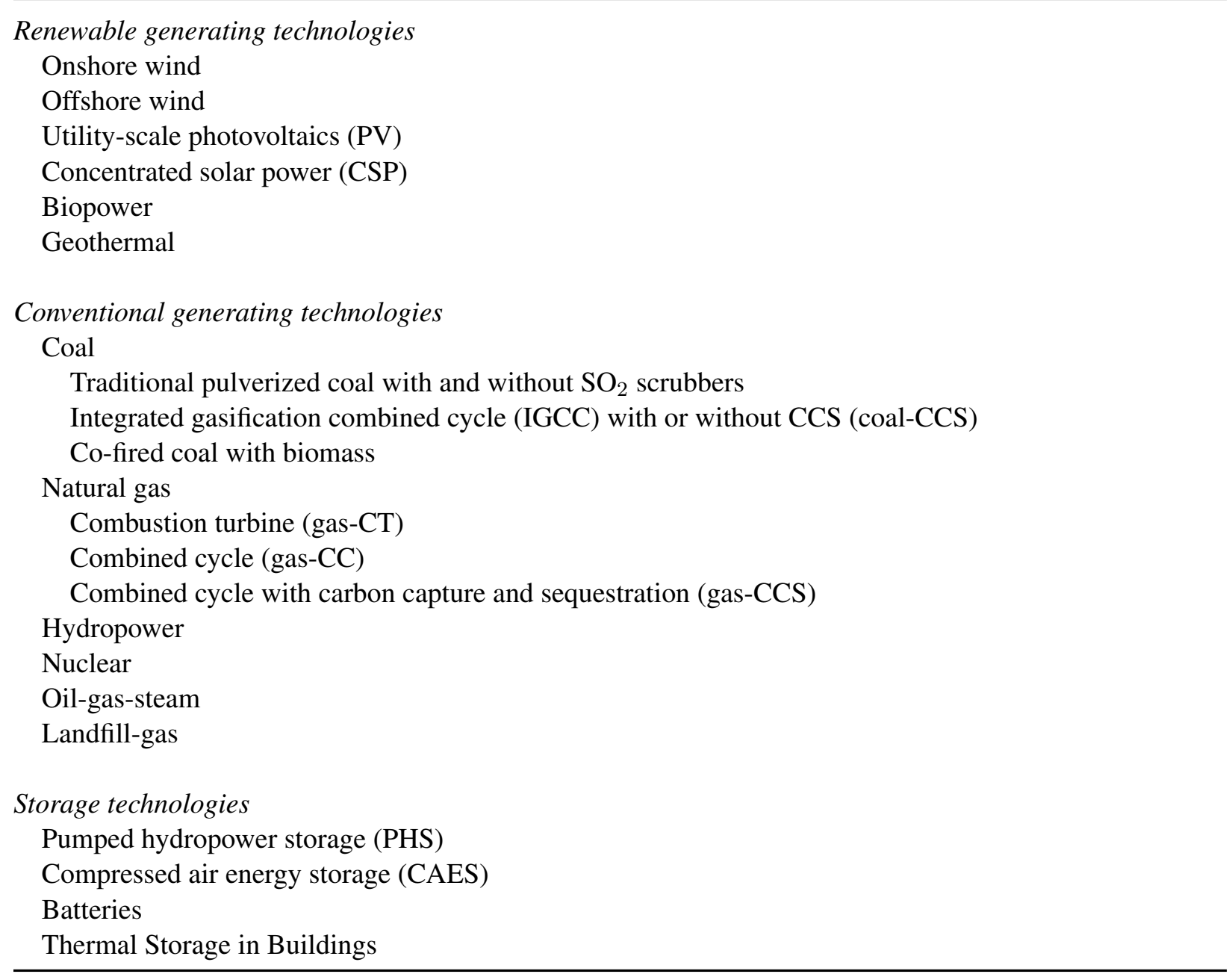

present value cost of adding new generation capacity and operating it (considering transmission and operational integration) over an assumed financial lifetime (20 years for the present study). This cost minimization routine is applied for each two-year investment period between 2006 to 2050.

A comprehensive documentation including data and model structure is available online (Short et al., 2009). Here, we focus on highlighting the model features relevant for characterizing renewable energy supplies.

\subsubsection{Renewable Energy Supplies}

ReEDS uses 356 different resource regions in the continental U.S. to characterize wind and concentrated solar power (CSP) resource. Data inputs are derived from a detailed geographic information system (GIS) model/database of the wind and CSP resource and transmission grid. This database is used to calculate supply curves of wind and CSP, which capture sub-regional resource quality variations and transmission costs, among other factors. Regional resource quality 

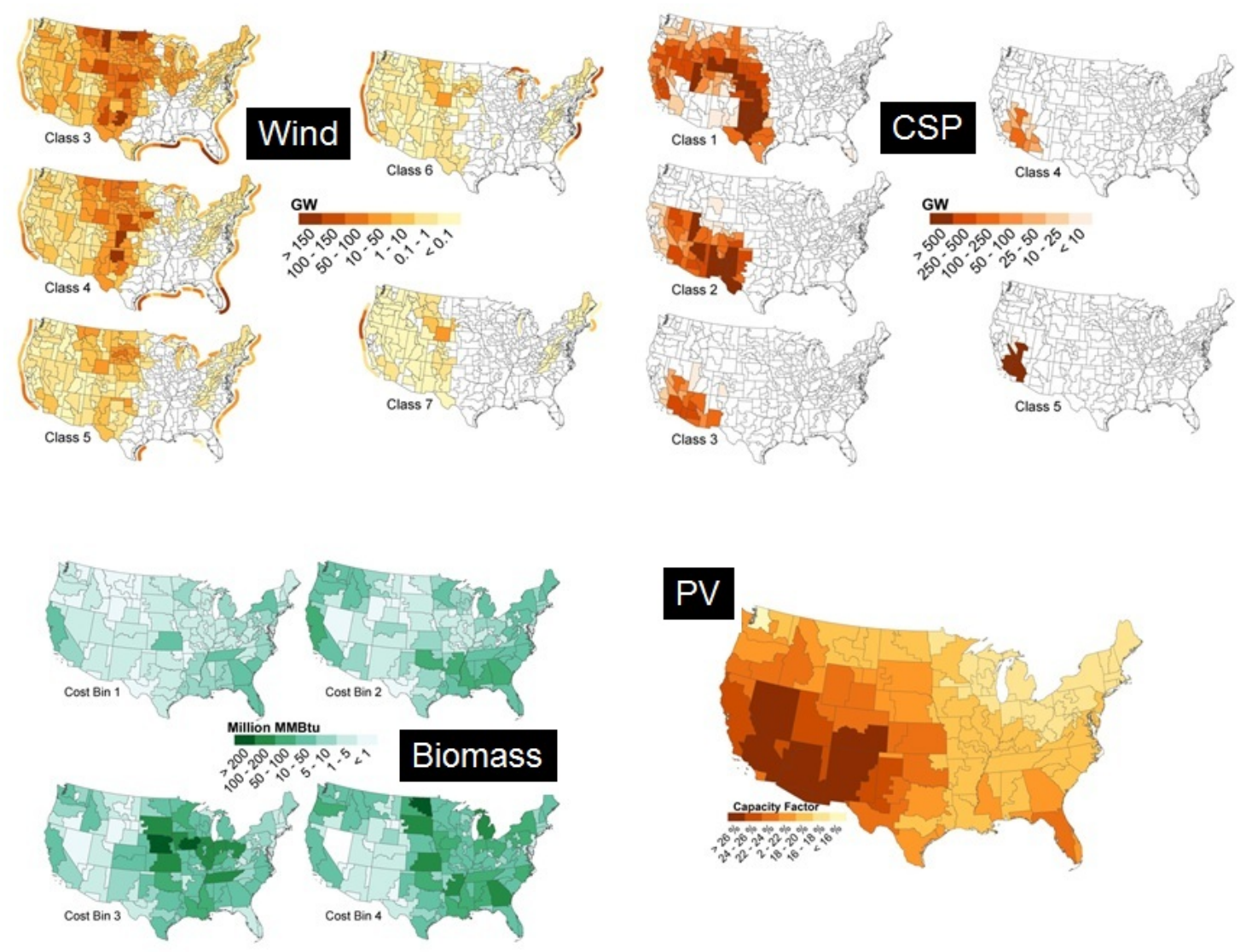

Figure 2. Regional resource resolution for wind, CSP, biomass, and PV.

variations are also considered for other renewable generator types, including hydropower, biopower, and geothermal. ReEDS provides supply curves for these resources in each of the 134 BAs. Figures 2-4 show the resource resolution for wind, CSP, biomass, PV, hydropower, and geothermal.

ReEDS considers five resource classes for wind based on wind power density and wind speed at 80 meters above ground. Available land area of each wind class in each CSP/wind resource region is derived from state wind resource maps and modified for environmental and land-use exclusions (see Short et al., 2009). The available wind area is converted to available wind capacity using a constant multiplier of $5 \mathrm{MW} / \mathrm{km}^{2} .{ }^{10}$

CSP performance for each CSP resource class was developed using typical DNI year (TDY) hourly resource data National Renewable Energy Laboratory from representative sites of each CSP/wind resource region. The TDY weather files were processed through the CSP modules of the Solar Advisor Model (National Renewable Energy Laboratory, 2010) for each type of CSP

\footnotetext{
${ }^{10}$ Fixed-bottom and floating-platform wind resource were differentiated based on water depth, where fixed-bottom resources correspond to a shallow water depth of less than 30 meters and floating-platform corresponds to deeper locations.
} 


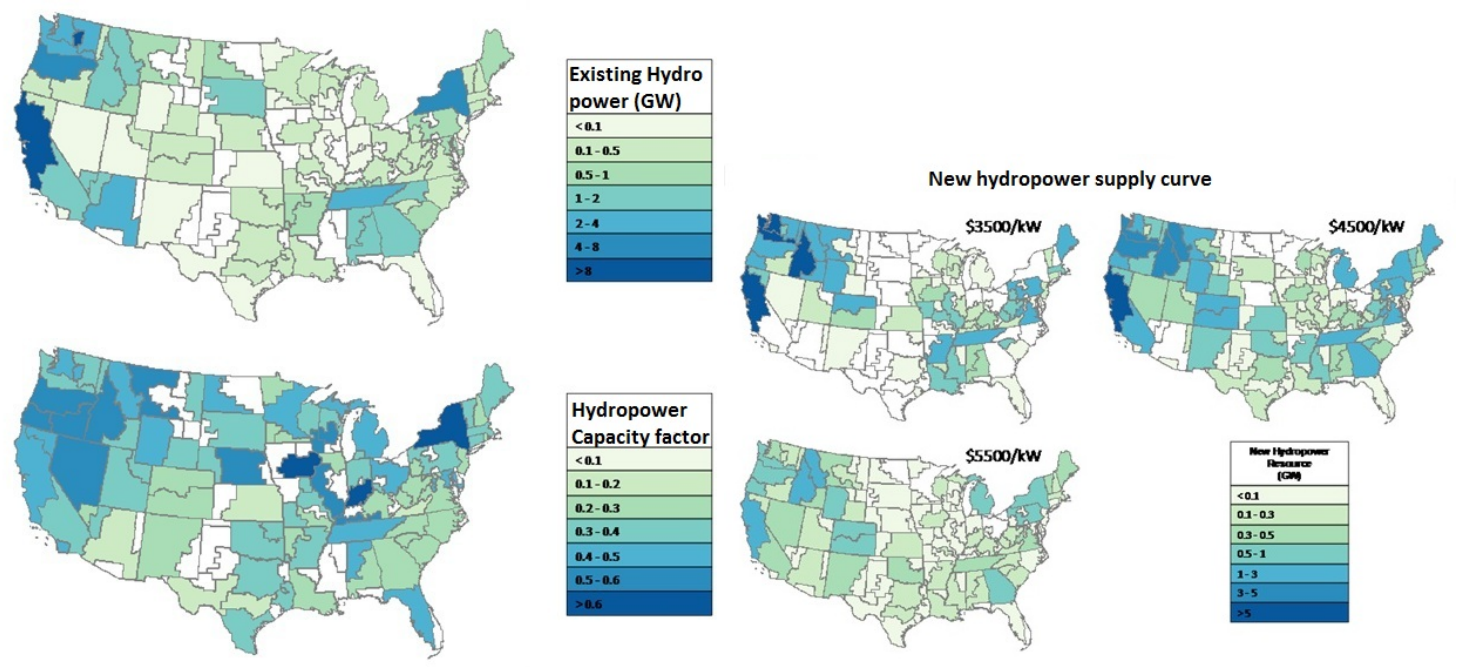

Figure 3. Existing (2010) hydropower capacity, average hydropower capacity factor for each Power Control Area, and new hydropower supply curve.
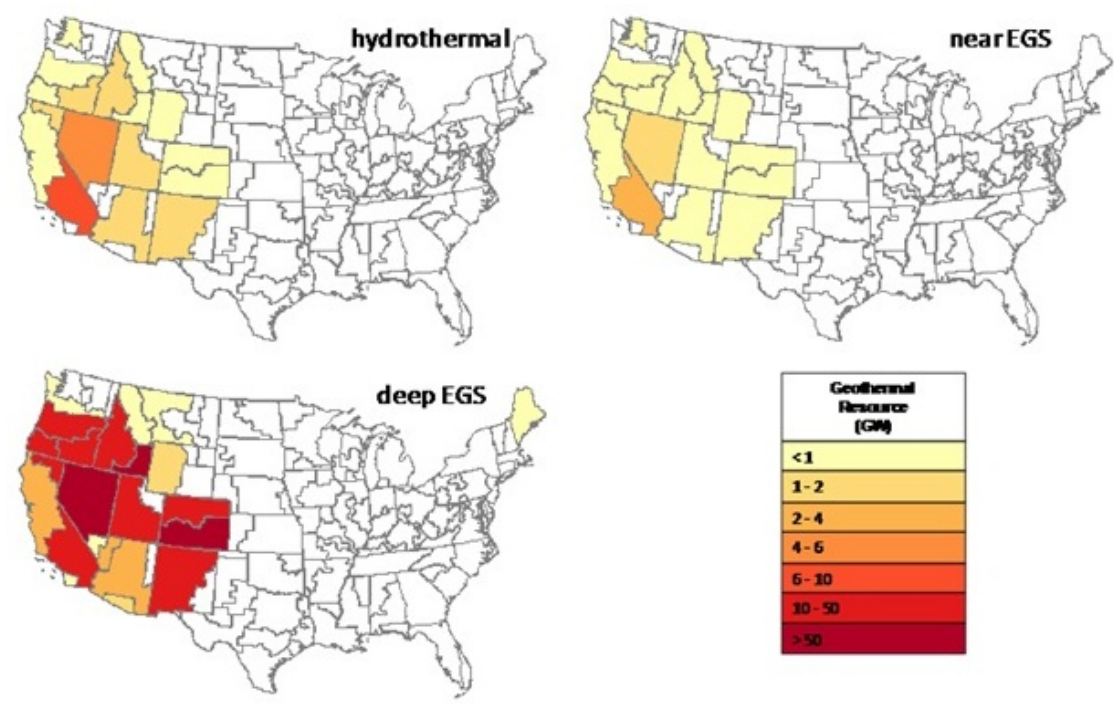

Figure 4. Geothermal (hydrothermal and enhanced geothermal systems) resources.

system considered in ReEDS. From this, capacity factors for each CSP resource class in each ReEDS time-slice were developed. The CSP resource classes are defined as follows. Class 1 5-6.25 kWh/m²/day; Class 2: $6.25-7.25 \mathrm{kWh} / \mathrm{m}^{2} /$ day; Class 3: $7.25-7.5 \mathrm{kWh} / \mathrm{m}^{2} /$ day; Class 4 : 7.5-7.75 kWh/m²/day; Class $5:>7.75 \mathrm{kWh} / \mathrm{m}^{2} /$ day.

Annual supply curves for the biomass feedstock (ORNL, 1999) have been disaggregated to the Power Control Area (PCA) level. The feedstock in the supply curve includes urban and mill waste, forest and agriculture residues, and dedicated crops. Dedicated crops are predominantly in the two most costly bins of the supply curve. The biomass supply classes are defined as follows. Class 1: 1.64\$/MMBtu; Class 2: 2.46\$/MMBtu; Class 3: 3.27\$/MMBtu; Class 4: 4.09\$/MMBtu. 
Central PV in ReEDS represents utility-scale single-axis-tracking PV systems with a representative size of $100 \mathrm{MW}$. Performance characteristics for central PV were developed by the PV module of Solar Advisor Model (NREL, 2010a) using weather from typical meteorological year (TMY) files located at all TMY3 stations throughout the contiguous U.S. (Wilcox and Marion, 2008). The TMY site with the highest predicted annual PV capacity factor in each ReEDS PCA was used to represent the performance (i.e., capacity factor in each time slice) of central PV capacity installed in that PCA.

The PCA-dependent annual capacity factors for hydropower are estimated based on the average historical annual generation from 1990 to 2007 Ventyx (2006). The capital cost supply curve of potential new hydropower capacity are based on a resource assessment in Short et al. (2009); three bins of hydropower resource, comprising $\$ 3500 / \mathrm{kW}, \$ 4500 / \mathrm{kW}$, and $\$ 5500 / \mathrm{kW}$, are considered. The resource assessment only considered run-of-river resources, though absent dispatch schedules and due to coarse time slices in ReEDS, the dispatch of the existing and new hydropower capacity is only limited by season.

Geothermal resources are concentrated in the Western interconnection with the sole exception of limited deep enhanced geothermal systems (EGS) resource in Maine. In each PCA, a separate capital cost supply curve is used to represent the available resource at a given cost. The PCA-level supply curves were developed by aggregating site-specific resource assessments (Short et al., 2009).

Variable resource renewable energy (VRRE) technologies, which include wind, CSP without storage, utility-scale PV, and distributed PV, produce power that is both variable, uncertain, and non-dispatchable. Generally, greater penetrations of these technologies leads to greater levels of curtailment, required operating reserves, as well as diminished contribution to planning reserve requirements per unit of VRRE capacity. ReEDS uses statistical calculations that rely on simulated hourly output data for wind, PV, and CSP to characterize the variance and co-variance of power output for each VRRE technology during each time slice. The calculations rely on the aggregate variability for each reserve-sharing group (for the present study, the reserve-sharing groups are assumed to be the 21 Regional Transmission Organization (RTO) regions). In general, greater geographical distance between two sites of the same resource leads to a lower degree of correlation between power outputs, thereby decreasing the variability of the combined generation. Because of these correlations, all else being equal, ReEDS will choose to spatially spread generators of the same resource to reduce aggregate variability in a reserve-sharing group.

\subsection{Model Integration}

In principle, a bottom-up representation of the electricity sector can be integrated directly within a GE framework by solving Kuhn-Tucker equilibrium conditions that arise from the bottom-up cost-minimization problem, along with general equilibrium conditions describing the top-down model (Böhringer and Rutherford, 2008). In applied work, this approach may be infeasible due to the large dimensionality of the bottom-up problem. Moreover, the bottom-up model involves a large number of bounds on decision variables, and the explicit representation of 


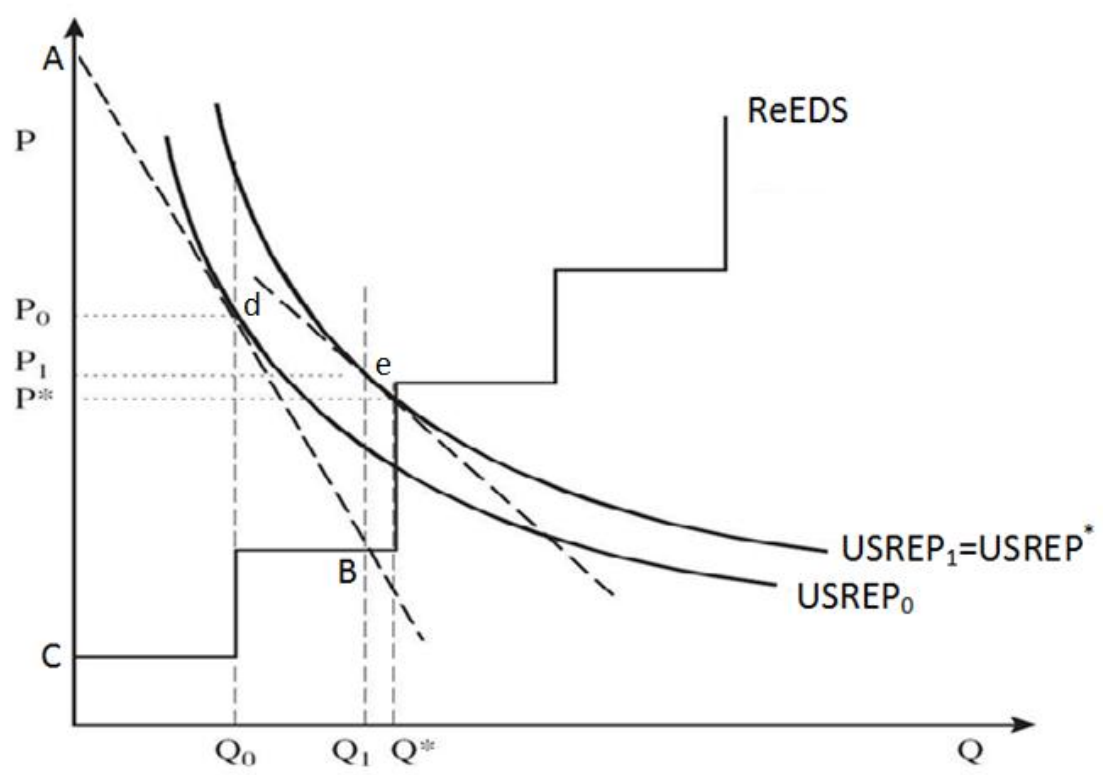

Figure 5. Iterative solution procedure between both models.

associated income effects becomes intractable if directly solved within a GE framework (Böhringer and Rutherford, 2009).

Our computational strategy is to use a block decomposition algorithm put forward by Böhringer and Rutherford (2009) that involves an iterative procedure between both sub-models solving for a consistent general equilibrium response in both models. The first step for implementing the decomposition procedure in an applied large-scale setting is the calibration of the two sub-models to a consistent benchmark point. Initial agreement in the base year is achieved if bottom-up electricity sector outputs and inputs for all regions and generators are consistent with the aggregate representation of the electric sector in the Social Accounting Matrix (SAM) data. ${ }^{11}$ To produce a micro-consistent SAM, a benchmarking routine was developed for the year 2006, the first modeled year, wherein ReEDS was solved with historical (fixed) prices for capital, labor, and fuel as well as fixed regional electricity demands. ${ }^{12}$ Given ReEDS electricity supplies and inputs demands, we use least-square optimization techniques to estimate a new SAM holding fixed the (simulated) electric sector data. Our benchmarking routine implies that, in absence of a policy shock, the integrated model is fully converged in the base year.

Each iteration in the solution algorithm comprises two steps. Step 1 solves a version of the USREP model with exogenous electricity production where electricity sector outputs and input

11 This step is necessary to ensure that in the absence of a policy shock iterating between both sub-models always returns the no-policy benchmark equilibrium. Violation of this initial condition means that any simulated policy effects would be confounded with adjustments due to initial data inconsistencies between the two sub-models.

${ }^{12}$ Wholesale electricity is an output of the ReEDS model, and remained so for the benchmarking routine. Electricity price distribution markups were estimated for each USREP region based on the difference between the historical 2006 retail electricity price and the wholesale electricity price from the first solve of the ReEDS model. 
demands for fuels, capital, labor, and other materials, are parameterized based on the last available solution of the ReEDS model. The subsequent solution of the ReEDS model in Step 2 is based on a locally calibrated set of regional demand functions for electricity and a vector of candidate equilibrium prices for fuels, capital, labor, and materials. The key insight from Böhringer and Rutherford (2009) is that a Marshallian demand approximation in the electricity sector provides a good local representation of general equilibrium demand, and that rapid convergence is observed as the electricity sector is small relative to the rest of the economy. ${ }^{13}$

Figure 5 shows qualitatively how the models iterate on the electricity price $(P)$ and demand $(Q)$, where $P_{0}$ and $Q_{0}$ represent the initial guesses, $P_{1}$ and $Q_{1}$ represent the second guess, and $P *$ and $Q *$ represent the final converged solution. To create a basis for iteration, non-linear electricity demand from the CGE model is approximated with a regional demand function in ReEDS that is locally calibrated based on the solution of the CGE model (i.e. points $d$ and $e$ in Figure 5). ${ }^{14}$ For all other commodities, USREP simply passes commodity prices to ReEDS, and ReEDS treats these prices as parameters for a given iteration. Both sub-models are recursive-dynamic implying that convergence between both sub-models is first established for given time period before moving forward in time.

As the present study represents the first application of the decomposition technique in a large-scale applied setting, there are a number of issues and extensions of the original method that warrant further discussion. First, incorporating a demand response in ReEDS requires modifying the objective function. Instead of minimizing total system costs, as is the case for the native version of the ReEDS model, the integrated model chooses generation, transmission, and capacity decisions for each two-year period in the electric sector that maximize the sum of regional consumer and producer surpluses (graphically shown by the area ABC in Figure 5). ${ }^{15}$ Second, commodity prices and demands are transferred between the economic and electric sector model at the regional level shown in Figure 5. To incorporate regional commodity price variation on technology and fuel costs, ReEDS maps its 134 BAs and 356 resource regions to the 12 USREP regions. Third, a consistent integration of both models needs to capture all profits earned by sub-marginal generators in the electric sector. Profits or rents arise because of capacity, transmission and resource constraints. In ReEDS the producer surplus represents the sub-marginal profits of technologies/generators that produce electricity at a cost that is smaller than the cost of the marginal generator and sell it at the market price which in equilibrium is equal to the marginal cost. For each region, we can calculate total sub-marginal profits as the difference between the value of electricity output and the value of inputs used to produce electricity. Profits

${ }^{13}$ In our simulations, rapid convergence is observed-usually six to nine iterations are needed-as the electricity sector is small relative to the rest of the economy. The U.S. electric sector represents less than 4\% of GDP.

14 The demand curves represent annual electricity demand. We uniformly scale electricity demand in each time slice, i.e. diurnal and seasonal profiles for electricity demand remain fixed throughout the solution procedure.

15 The optimization of the sum of consumer and producer surplus results in a non-linear (quadratic) programming problem. We linearize the quadratic component of the objective function to be able to solve the ReEDS model as a linear program. 
accrue to owners of generation and transmission capacity and are distributed proportional to capital income. ${ }^{16}$ Fourth, implementing an economy-wide carbon policy in the integrated model requires iterating on the price of carbon and the demand for $\mathrm{CO}_{2}$ emissions permits. We thus pass a candidate carbon price from USREP to ReEDS, and the subsequent solution of USREP then calculates a new estimate for the equilibrium carbon price based on demands for emissions permits by the electricity and non-electricity sectors.

\section{SIMULATION RESULTS}

\subsection{Scenarios and Assumptions Underlying the Simulation Dynamics}

Our analysis focuses on the following five counterfactual scenarios whose specifications are outlined in the text below:

- BAU: "Business-as-usual" case without a federal CES or RES policy but existing state RES policies in the baseline.

- CES: Federal Clean Energy Standard.

- RES: Federal Renewable Energy Standard.

- CAT_CES: Federal cap-and-trade policy covering all sectors of the economy and achieving equivalent year-on-year $\mathrm{CO}_{2}$ emissions reductions as CES scenario.

- CAT_RES: Federal cap-and-trade policy covering all sectors of the economy and achieving equivalent year-on-year $\mathrm{CO}_{2}$ emissions reductions as RES scenario.

The CES scenario is constrained to achieve a certain clean electricity fraction target in each modeled year, defined as the ratio of total clean energy electricity generation to total electricity sales. The amount of generation from each technology that is considered clean depends on the technology. Specifically, all renewable technologies (wind, solar, hydropower, biopower, and geothermal) and nuclear are considered $100 \%$ clean, natural gas with carbon capture and storage (CCS) is considered 95\% clean, coal with CCS is considered $90 \%$ clean, and gas combined cycle is considered $50 \%$ clean. Both existing installations and new investments in these technology types earn a credit. ${ }^{17}$ The CES targets are assumed to increase linearly from $42 \%$ in 2012 to $80 \%$ by 2035 . Then targets increase linearly from 2035 to 2050 , achieving a final value of $95 \%$ in 2050. Our specification of the CES is therefore broadly consistent with the policy outlined by the Obama administration based on the 2011 State of the Union address and a white paper issued by the staff of the Senate Energy and Natural Committee on March 21, 2011.

Under the RES scenario all renewable technologies, including hydropower, are considered a $100 \%$ clean. No credits are given for any other technology. The RES targets are assumed to

${ }^{16}$ Lacking data on geographical ownership patterns of equity in the electric sector in the U.S., we use capital income as a proxy.

${ }^{17}$ Some CES proposals differ with respect to whether existing nuclear and hydro are treated. If they do not earn credits, existing hydro and nuclear would be treated no differently than coal facilities under a CES, which might seem perverse considering that an objective of the policy is to reduce emissions. A recent analysis by Palmer et al. (2011b) using the Haiku electricity model suggests that this feature of the policy may lead to a different outcome in terms of regional electricity price impacts. 
increase linearly from $20 \%$ in 2012 to $70 \%$ in 2050.

For each of the federal CES and RES policies, we implement a corresponding CAT scenario that achieves the same level of economy-wide annual $\mathrm{CO}_{2}$ emissions in each modeled year. This enables us to focus on the cost-effectiveness of the policies while holding fixed the environmental impact. In our model, these two scenarios can also be equivalently thought of as a federal carbon tax policy where tax rates over time equal the trajectory of equilibrium permit prices.

In addition, the following assumptions apply to our analysis. First, trading in CES credits is national in scope and trades across state borders are not limited. As a consequence, some states or regions will be net seller of CES credits and others will be net buyers with ensuing regional transfers of wealth. Second, banking of CES credits is not modeled, so a MWh of clean electricity generated in a particular year must be used for compliance in the same year. We also do not consider borrowing of CES credits. For consistency across policy scenarios, we assume that emissions permits also cannot be banked or borrowed. Third, we require that each policy has to be revenue-neutral which is implemented by requiring the same level of government expenditure (in real terms) as in the BAU. Balance of the government budget is achieved through an endogenous non-distortionary lump-sum tax. Fourth, for the CAT policy we assume that the revenue from emissions permits (net of what is withheld to maintain revenue-neutrality for the government budget) is distributed lump-sum to households on a per-capita basis. ${ }^{18}$ Fifth, existing state RES policies are included in our baseline. We assume that these programs continue to exist in our counterfactual scenarios but that credits from a federal CES are not tradable with state/regional RES programs. Lastly, our analysis does not consider alternative compliance payments (ACP) for CES credits where regulated entities could make such payments in lieu of purchasing credits. ACPs would limit the costs to the economy of imposing a CES by essentially establishing a cap on the price of CES credits-albeit at the expense of failing short to meet environmental targets. ${ }^{19}$

\subsection{National Impacts}

\subsection{1 $\mathrm{CO}_{2}$ Emissions}

A CES (RES) policy as specified above will reduce cumulative $\mathrm{CO}_{2}$ emissions in the U.S. electricity sector between 2012 and 2050 by roughly 51 (33)\%, or 48.5 (31.4) billions tons, relative to a baseline with no CES/RES policy. These reductions correspond to a cut of 17 (11)\% in terms of economy-wide cumulative emissions for the CES and RES scenario, respectively.

The size of annual emissions reductions will grow over time as the standards tighten (Figure 6). The CES policy is significantly more aggressive reducing emissions from electricity to $39 \%$

\footnotetext{
${ }^{18}$ We therefore implicitly assume that emission permits are fully auctioned. Alternatively, our scenario can also be viewed as one that freely allocates allowances ensuring that consumers fully perceive the carbon price signal. For example, this rules out cases where the value of freely allocated allowances is passed on to consumers in the form of a subsidy to electricity prices either because the CAT regulation explicitly aims at sheltering some electricity consumers or because the intent of the legislation to have electricity prices reflect the full $\mathrm{CO}_{2}$ costs is frustrated by Public Utility Commission's rate setting (Burtraw et al., 2001).

${ }^{19}$ Palmer et al. (2011a) provide an analysis of the effects of ACP on the performance of a federal RES policy.
} 

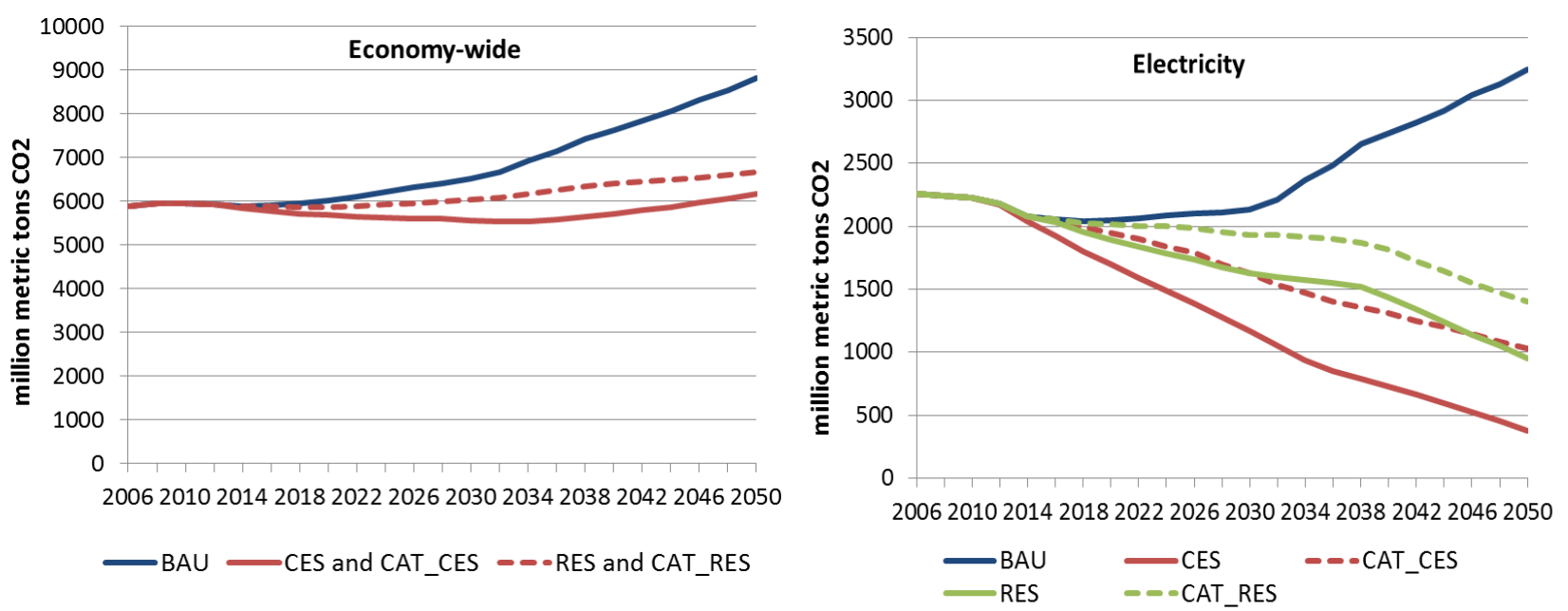

Figure 6. National economy-wide and electric sector $\mathrm{CO}_{2}$ emissions.

and $155 \%$ below the respective RES levels in 2030 and 2050. Up until 2038, the rate of emissions reductions is much bigger for the CES policy and then becomes more similar during the last ten years of the policy.

The CAT_CES and CAT_RES scenarios will lead to 34 and $22 \%$ cumulative emissions reductions from electricity relative to the baseline, respectively, implying that both energy standards will lead to roughly 1.5 times higher cumulative emissions reductions in the electricity sector as compared to the respective cap-and-trade scenario. This suggests that a policy focused only on the electric sector will forgo low-cost abatement opportunities in other sectors of the economy that would be realized if marginal cost of abatement were equalized across all $\mathrm{CO}_{2}$ emitting activities - as would be the case under a comprehensive federal cap-and-trade regulation.

\subsubsection{Cost-effectiveness}

Table 5 compares national welfare impacts across scenarios. Change in welfare is measured in equivalent variation (EV) as a percentage of full income, where full income includes material consumption and leisure. Table 5 reports a weighted average of each household's EV where a household's weight is proportional to its share in the total population. Holding fixed year-on-year emissions across each pair of policies enables us to assess the cost-effectiveness of CES/RES policies relative to the respective cap-and-trade policy.

Both regulatory standards for the electricity sector are highly cost-ineffective. Taking a net present value (NPV) perspective, the CES (RES) is 1.9 (4) times more costly than a cap-and-trade policy that would achieve the same $\mathrm{CO}_{2}$ emissions reductions. Because the set of credited technologies is larger under the CES, in particular allowing full crediting of nuclear and partial crediting of "clean" natural gas and coal, the CES is more cost-effective relative to the RES which achieves compliance by mainly deploying high-cost wind and solar power. Note that this holds true even though the RES is significantly less aggressive in terms of observed emissions 
Table 5. National welfare impacts.

\begin{tabular}{|c|c|c|c|c|c|c|}
\hline & \multicolumn{4}{|c|}{ Equivalent Variation } & \multicolumn{2}{|c|}{ Relative Efficiency } \\
\hline & CES & CAT_CES & RES & CAT_RES & $\begin{array}{r}\text { Ratio CES/ } \\
\text { CAT_CES }\end{array}$ & $\begin{array}{r}\text { Ratio RES/ } \\
\text { CAT_RES }\end{array}$ \\
\hline \multicolumn{7}{|l|}{ Annual impacts (\%) } \\
\hline Year 2020 & -0.10 & -0.03 & -0.05 & -0.01 & 3.9 & 7.3 \\
\hline Year 2030 & -0.48 & -0.24 & -0.26 & -0.07 & 2.0 & 3.6 \\
\hline Year 2050 & -0.62 & -0.47 & -0.40 & -0.19 & 1.3 & 2.1 \\
\hline \multicolumn{7}{|c|}{ Net present value impacts ${ }^{a}$} \\
\hline Percentage change & -0.37 & -0.20 & -0.17 & -0.04 & 1.9 & 4.0 \\
\hline Billion $2006 \$$ & $-1,974.3$ & $-1,043.0$ & -907.2 & -227.8 & 1.9 & 4.0 \\
\hline $\begin{array}{l}\text { Annual average per } \\
\text { household in } 2006 \$\end{array}$ & -392 & -204 & -180 & -44 & & \\
\hline
\end{tabular}

Notes: Welfare impacts refer to population-weighted national averages. ${ }^{a}$ Discounted at $4 \%$ per year.

reductions than the CES. This suggests that a technology mandate in the electricity sector targeted at deploying a substantial amount of renewables without allowing "clean" fossil-based generating technologies to play a role will entail significant economic costs and will not be cost-effective.

Comparing the cost-effectiveness for different sub-periods of the policy horizon shows that the relative inefficiency of regulatory policies appears to be particularly large for the first 10-20 years, but that it decreases substantially over time. This suggests that cheaper abatement options in other sectors of the economy are available in the years following the introduction of the policy, but that these are limited. Consequently, any cost-effective climate policy set out to achieve sizable economy-wide $\mathrm{CO}_{2}$ emissions reductions over the next decades, will have to eventually involve substantial abatement from the electricity sector.

\subsubsection{Distributional Impacts by Income}

Table 6 shows NPV welfare changes by income class across scenarios. Both the CES and RES policies are regressive, i.e. low-income household bear a disproportionately large burden of the economic cost. There are two key drivers for this result. First, the increase in electricity prices under a CES/RES disproportionately affects low-income households who spend a larger fraction of their budget on electricity (regressive uses side effect). Second, capital owners benefit from returns on new investments in clean generating capacity. High-income households disproportionately benefit as they exhibit higher capital income shares relative to low-income households (progressive sources side effect).

The pattern of distributional impacts across income groups can be quite different under an economy-wide, federal cap-and-trade program. Assuming that the carbon revenue is returned lump-sum on a per-capita basis, both the CAT_CES and the CAT_RES are progressive. Note that this is not a general result as distributional effects depend crucially on how the carbon revenue 
Table 6. National welfare impacts by income.

\begin{tabular}{|c|c|c|c|c|c|c|c|c|}
\hline \multirow{2}{*}{$\begin{array}{l}\text { Income group } \\
(\$ 1,000 \text { annual income })\end{array}$} & \multicolumn{2}{|c|}{ CES } & \multicolumn{2}{|c|}{ CAT_CES } & \multicolumn{2}{|c|}{ RES } & \multicolumn{2}{|c|}{ CAT_RES } \\
\hline & $\%$ & $\$$ & $\%$ & $\$$ & $\%$ & $\$$ & $\%$ & $\$$ \\
\hline$<10$ & -0.54 & -264 & 1.50 & 753 & -0.31 & -147 & 1.09 & 533 \\
\hline $10-15$ & -0.50 & -265 & 0.52 & 287 & -0.27 & -142 & 0.44 & 235 \\
\hline $15-25$ & -0.49 & -289 & 0.29 & 184 & -0.25 & -147 & 0.29 & 177 \\
\hline $25-30$ & -0.46 & -346 & -0.07 & -46 & -0.23 & -171 & 0.05 & 42 \\
\hline $30-50$ & -0.40 & -402 & -0.28 & -274 & -0.19 & -191 & -0.09 & -88 \\
\hline $50-75$ & -0.38 & -438 & -0.46 & -536 & -0.17 & -194 & -0.21 & -245 \\
\hline $75-100$ & -0.35 & -473 & -0.33 & -437 & -0.16 & -208 & -0.13 & -173 \\
\hline $100-150$ & -0.33 & -456 & -0.33 & -455 & -0.14 & -191 & -0.13 & -183 \\
\hline$>150$ & -0.31 & -499 & -0.47 & -770 & -0.12 & -198 & -0.23 & -369 \\
\hline Average & -0.37 & -392 & -0.2 & -204 & -0.17 & -180 & -0.04 & -44 \\
\hline
\end{tabular}

Notes: Welfare impacts are population-weighted averages of net present value (NPV) of equivalent variation by household. "\$" refer to annual averages of NPV welfare impacts expressed in 2006 .

from a cap-and-trade policy is distributed (or how freely allocated emissions permits are distributed). In fact, our per-capita allocation rule adds to the progressivity of the policy because $\$ 1$ dollar of revenue allocated to a low-income household represents a larger share of income than $\$ 1$ dollar allocated to a high-income household.

One important implication that follows from Table 6 is that a first-best market-based policy such as a cap-and-trade program or a carbon tax generates revenue that can be used to alter unintended distributional consequences of the policy. On the other hand, a CES or RES program is essentially a revenue-neutral credit trading system that induces offsetting payments between "clean" and "dirty" electricity generators. Thus, besides being cost-ineffective, a CES or RES policy does not generate any revenue that could be used to address concerns over distributional outcomes. $^{20}$

\subsubsection{Electricity Price Impacts and Equilibrium Permit Prices}

Figure 7 shows the evolution of the U.S. average retail electricity price across different scenarios and reports equilibrium CES/RES credit prices as well as carbon price for both CAT cases. While for all policy cases price impacts are similar by 2050, showing increases on the order of $15 \%$ relative to BAU, the equilibrium price trajectories leading up to 2050 for the CES/RES are below the one for the respective CAT case. Differences in price impacts across scenarios are the largest for the initial years after the introduction of the policy and the price gap between CES/RES and CAT policies narrows over time converging in all cases to a price level of around 16.5 cents per $\mathrm{kWh}$ in 2050 .

${ }^{20}$ Of course, additional policy measures to address distributional issues are conceivable, but one should be clear that those would go beyond what is intended under a purely technology-focused CES or RES policy. 

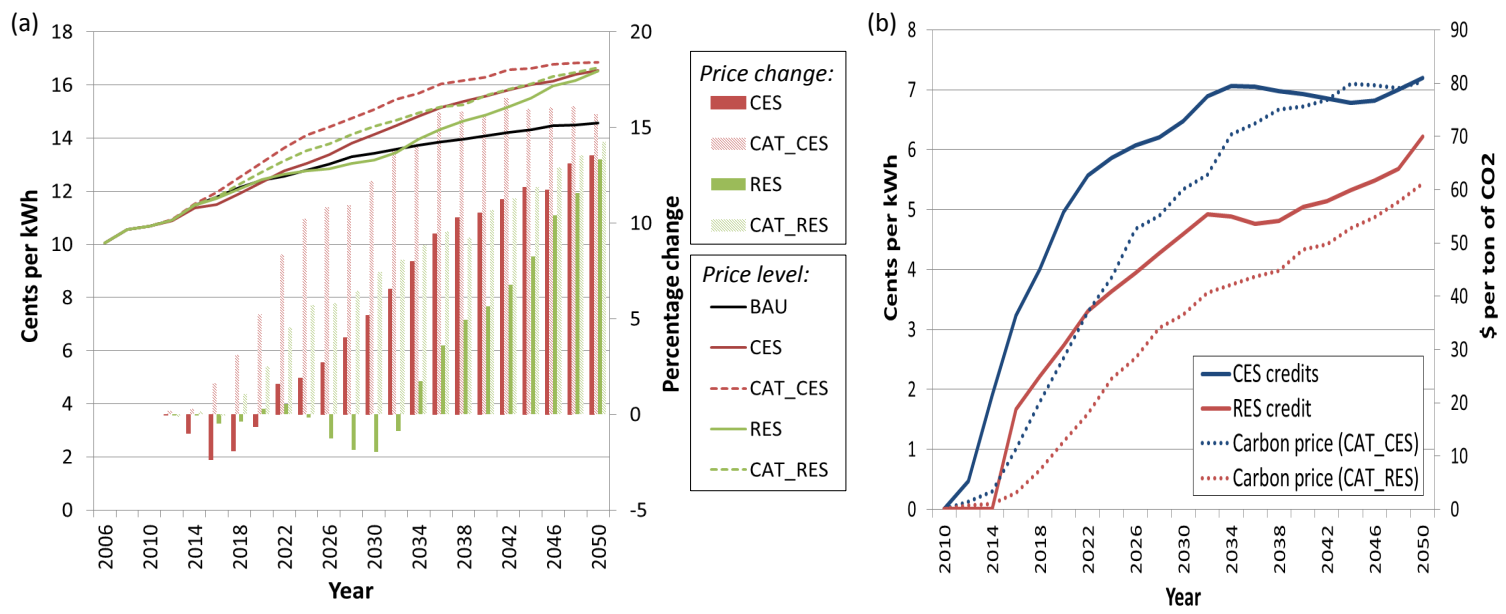

Figure 7. U.S. average retail electricity price (a) and CES/RES credit and carbon prices (b).

Differences in price impacts are due to the nature of policy instruments. First, under the CES/RES dirty, fossil-based generators are taxed and the credit revenue is used to effectively subsidize electricity production from clean energy sources. In contrast, under a CAT policy the revenue from imposing a carbon charge on fossil-based generators is passed forward to consumers in the form of lump-sum payments instead of subsidizing electricity prices. Second, by directly incentivizing the deployment of electricity from renewable energy sources, the CES/RES policies push in low-cost generation options that enter the dispatch order at the front end thus pushing out the existing supply curve and lowering marginal costs. The CAT policy mainly leads to a reduction in the use of coal with less deployment of renewable electricity. Over time, as low marginal-cost options for renewable electricity are gradually used up and as CES/RES targets become more stringent, price impacts across policies converge. ${ }^{21}$

Equilibrium CES and RES credit prices displayed in Figure 7 suggest that both policies are binding immediately after their introduction. CES credit prices rise sharply to 7 cents per kwh in 2034 and remain at roughly this level for the later years of the program. The RES starts to be binding in 2014 with credit prices rising sharply until 2034 and a more gradual increase afterwards. Credit price trajectories under both the CES and RES suggest that a low alternative

${ }^{21}$ Negative price changes are observed for both the CES and RES before 2034. This can be explained by the fact that the CES requirement reduces coal capacity factors, allowing for spare coal capacity to be used to meet marginal demand requirements inexpensively: wholesale competitive electricity prices reflect both the fixed (i.e. capital and fixed operation and maintenance) and variable (i.e. fuel and variable operation and maintenance) costs of accommodating an additional marginal unit of demand. A CES requires that a certain fraction $f$ of this marginal unit must be clean generation, while the remaining fraction $(1-f)$ may be dirty generation. The CES policy forces coal plants to operate at less than their maximum capacity factors, so no additional capacity is required to meet the dirty fraction $(1-f)$ of the marginal unit of demand and therefore no fixed costs are required for that fraction. The BAU scenario, on the other hand, does not have this beneficial marginal price effect as most coal units are operating at full potential. Thus, even though total (fixed plus variable) costs of clean generation are higher than dirty generation, competitive prices may be lower under the CES. Also note that this effect is exaggerated at lower values of $f$, i.e. prior to 2034 . 
compliance payment, such as 2.1 cents per $\mathrm{kWh}$, as in some recent CES and RES proposals, would be binding from 2014 onwards and would therefore imply substantially less deployment of clean generation technologies as well as lower $\mathrm{CO}_{2}$ emissions reductions.

An important conclusion from comparing electricity price and welfare impacts is that a policy ranking based on electricity price impacts is misleading, i.e. one might be lead to favor clean or renewable energy standards over a first-best carbon pricing policy such as a cap-and-trade or carbon tax program that minimizes efficiency costs associated with reducing carbon emissions.

\subsubsection{Electricity Generation and Installed Generation Capacity}

Figure 8 shows electricity generation and installed capacity by technology type in each scenario over time through 2050. In the BAU, the model shows an increasing dependence on fossil fuels, with $72 \%$ of total electricity generation coming from coal or gas by 2050 , compared to $68 \%$ in 2010 . Renewables technologies, including hydropower, provide $20 \%$ of total generation by 2005 . The CES, on the other hand, reduces conventional gas and coal generation to $11 \%$ of total generation by 2050 , while renewable technologies provide $51 \%$ of total generation and nuclear provides $38 \%$. As the scope of the CAT_CES scenario is economy-wide, transformation of the electric sector is not as large as in the CES. Coal and gas generation reduces to $28 \%$ of total generation by 2050 , and renewable generation increases to $52 \%$ of total generation by 2050 , while the share of generation from nuclear power remains very near $20 \%$, similar to its share in 2012 . While the RES mandates that $70 \%$ of total generation has to come from renewable energy by 2050 , it brings about a significantly smaller reduction in coal and gas generation which contributes around $33 \%$ of total generation by 2050 .

Figure 9 enables a better comparison of US installed capacity and generation by technology, focusing on 2030 and 2050. Of the renewable generators, wind power in particular sees substantial growth in all policy scenarios, achieving near $26 \%$ of generation by 2050 in both the CES and CAT_CES scenarios. In these policy scenarios, onshore wind contributes $19 \%$ of total generation by 2050 but offshore wind installations also play a non-negligible role contributing to around $7 \%$. The share of hydropower only slightly increases from $6 \%$ under BAU to $8 \%$ in CES and CAT_CES in 2050. The second largest growth in terms of generation shares among renewable technologies is observed for biomass electricity (including co-fired biomass) which contributes $6 \%$ under CES and CAT_CES and 12\% under RES by 2050 compared to BAU levels of around $1 \%$ in 2050 . Biopower is closely followed by solar which provides $6 \%$ under CES and CAT_CES and $11 \%$ under RES by 2050. The generation share of geothermal is about $3 \%$ in 2050 under the BAU case and is largely unaffected by the policies.

Figure 10 shows annual wind capacity installations and cumulative wind capacity over time for the US. Wind growth experiences a period of rapid expansion until it reaches 350-370 GW of installed wind capacity, and then the growth rate slows substantially. This slowing of growth is due to a number of factors captured in the ReEDS model. For one, in its optimization ReEDS first chooses wind sites that are the most cost-effective in that they have the best combination of high capacity factors, nearness to transmission lines or population centers and therefore low transmission costs, and ability to fit well with temporal demand of electricity and the types of 

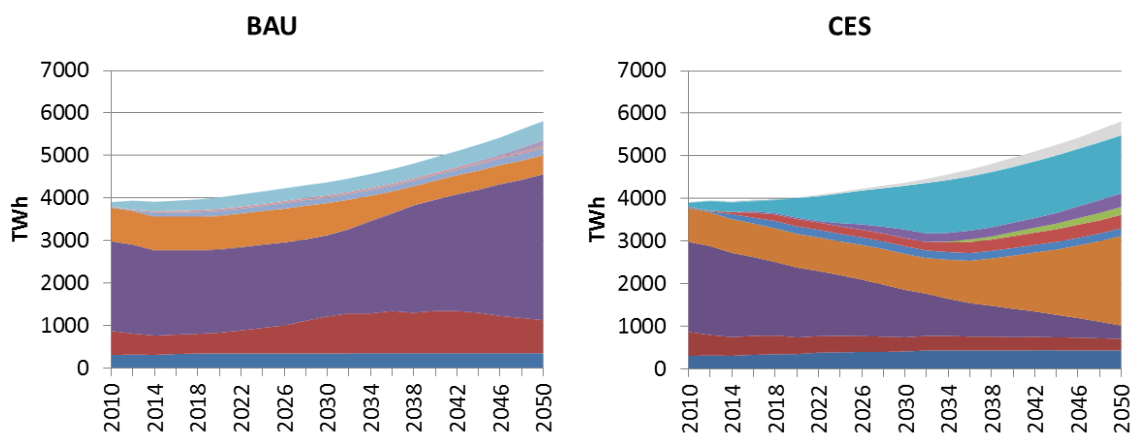

Demand red.

- Wind

IPV

CSP

- Biopower

- Geothermal

Nuclear

- Coal CCS

CAT_CES

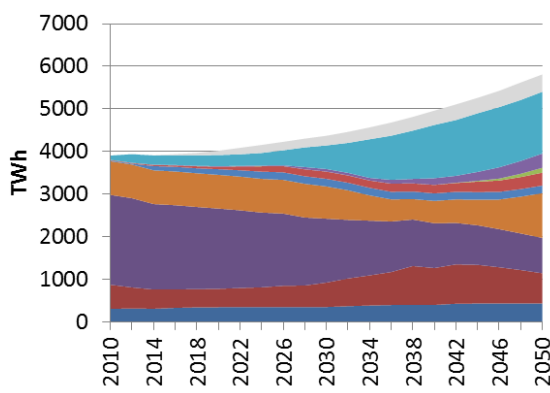

RES

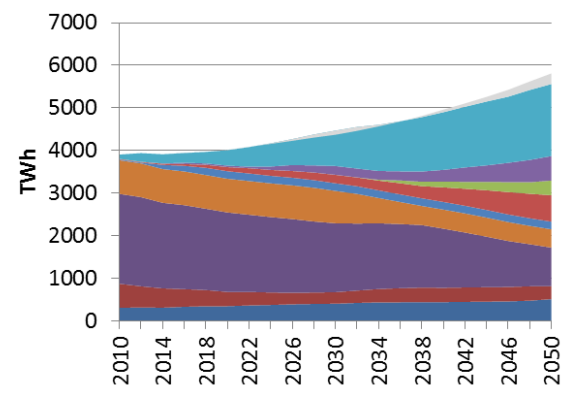

- Coal no CCS

- Gas CCS

- Gas no CCS

-Hydro

(a)
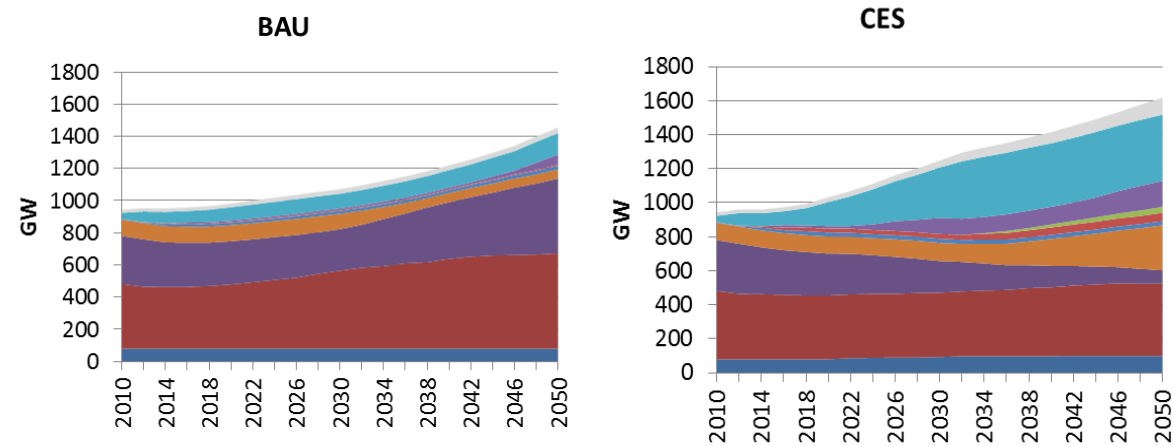

Storage

wind

口PV

- CSP

- Biopower

- Geothermal

nuclear

- Coal CCS

RES
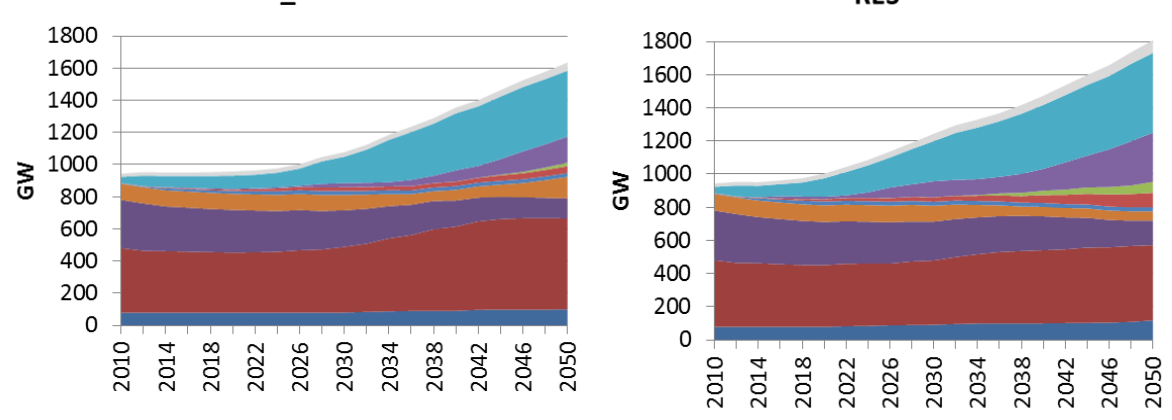

- Coal no CCS

- Gas CCS

- Gas no CCS

- Hydro

(b)

Figure 8. U.S. electricity generation (a) and installed generation capacity (b) by scenario over time. 

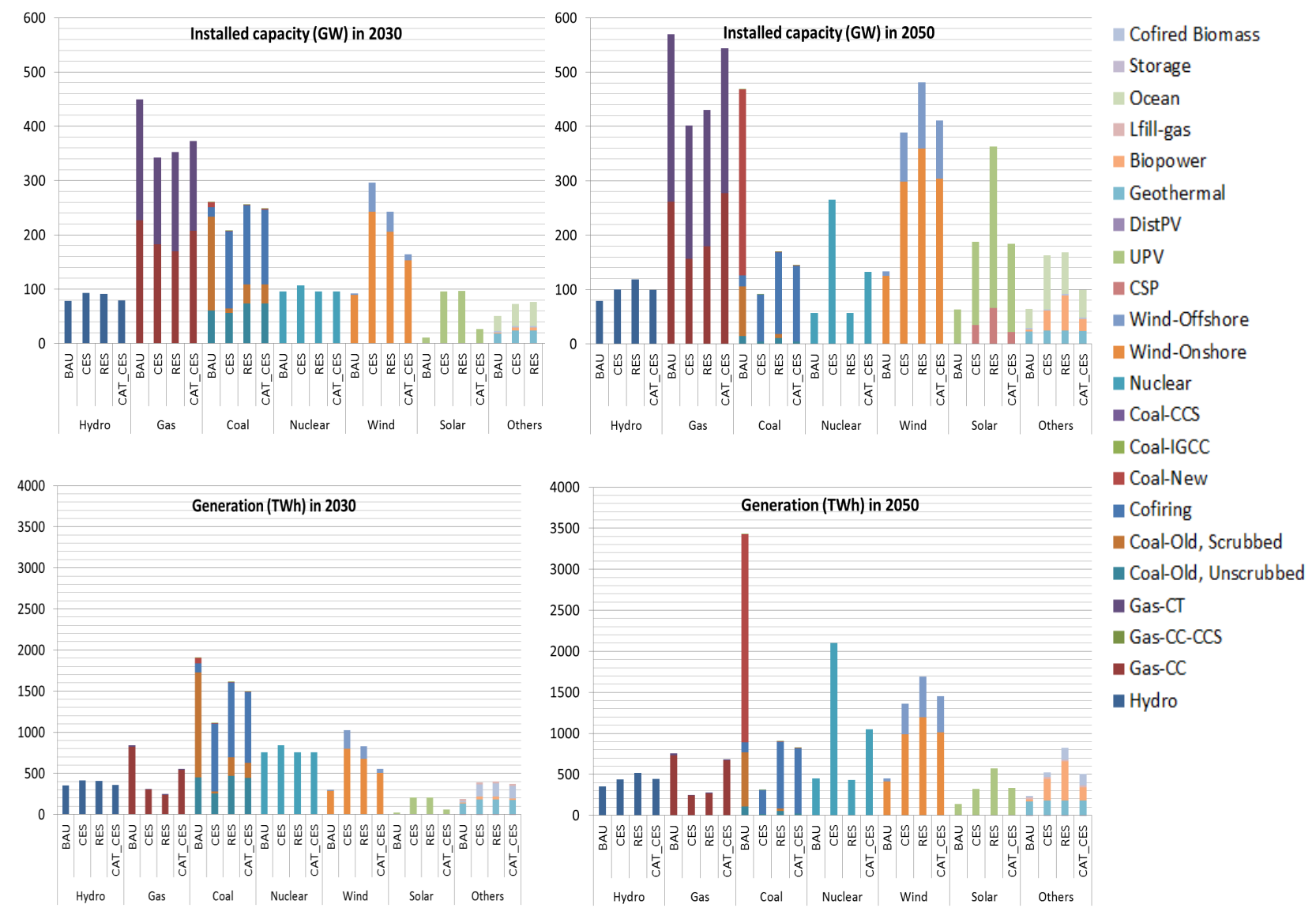

Figure 9. U.S. installed capacity and generation by technology in 2030 and 2050.
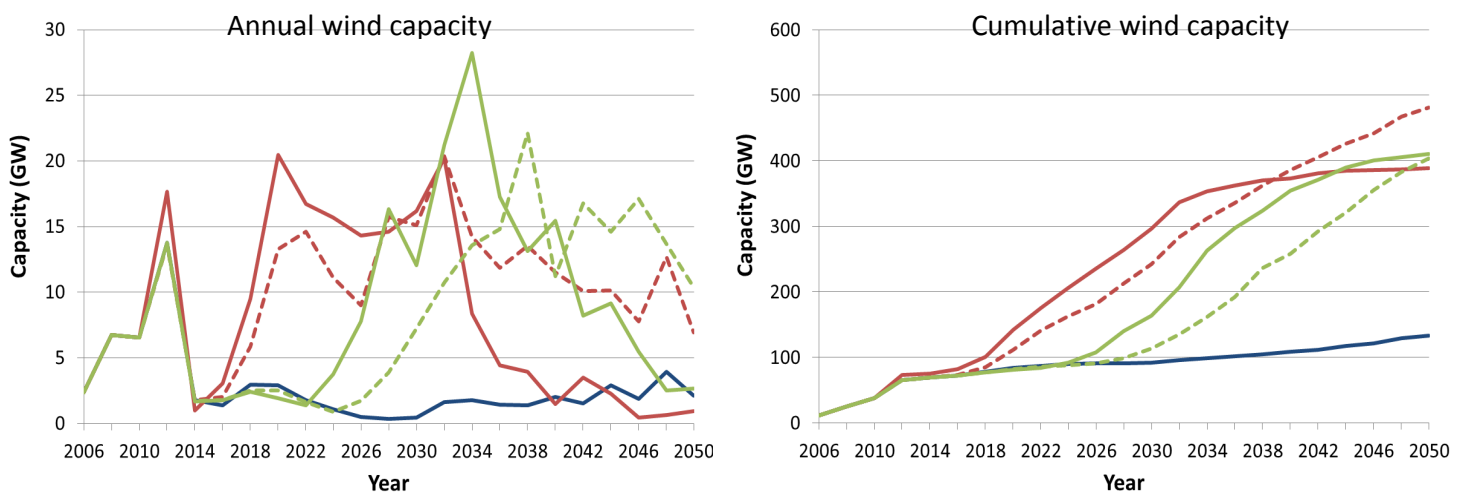

—BAU —CES - - RES —CAT_CES - - CAT_RES

Figure 10. U.S. annual wind capacity installations and cumulative installed wind capacity. 
generation technologies serving a region. As these sites are used up, incremental wind generation must move to lower quality sites. Furthermore, the increase in wind penetration reduces dispatchability of the system as a whole and increases variability, increasing the need for reserve capacity and increasing curtailments.

In the RES, cumulative installed wind capacity until 2036 is slightly lower than in the CES but the patterns of annual installations under both scenarios are similar. After 2036, annual wind capacity installations in the CES fall below $5 \mathrm{GW}$ whereas they remain at about the two-fold level in the RES through 2050. In the CES, the sharp decline in new wind capacity additions reflects the increased role of nuclear after 2034. In the RES, the nuclear option is not available and significant growth in wind is still required to meet the more stringent targets- together with significant growth in PV, CSP, and biopower after annual wind capacity installations peak in 2032. The growth in wind capacity before about 2023 is much slower in the CAT_CES and CAT_RES cases as most of the adjustment in the electricity sector is achieved through reducing the reliance on coal. As carbon prices continue to rise (not reported here) reaching levels of more than $\$ 70$ per metric ton of $\mathrm{CO}_{2}$ in the CAT_CES by 2034, annual wind capacity installations exceed those under the CES and RES. By 2050, the level of cumulative installed wind capacity across the different policy scenarios is relatively similar.

\subsection{Regional Impacts}

Table 7 shows NPV welfare impacts by region expressed as a percentage change and as a per-household annual average dollar impact relative to the BAU. Regions are ordered from the top to the bottom by their percentage welfare impacts for the CES. Both a federal CES and RES policy lead to an unequal distribution of economic costs with a maximum difference of 0.88 and 0.71 percentage points (or \$745 and \$636 annual costs per household) across regions, respectively. The CES and RES generate negative welfare impacts for all regions, while there are some regions in the CAT cases that experience welfare gains. The fact that some regions benefit from a cap-and-trade policy is not to say that carbon pricing itself is beneficial but that these regions receive transfer payments due to the allocation of the carbon revenue that overcompensate their abatement costs. Regions benefiting from a federal CAT policy are coastal regions - California, New England, New York, and Florida - that have already de-carbonized their economies to a large extent and that are relatively populous, thus benefiting from a per-capita allocation scheme.

Regional welfare impacts under the CES and RES can be traced back to electricity price impacts by region (Table 8) which in turn can be related to the generation mix in the baseline and the policy cases (Figures 11 to 12). ${ }^{22}$ In general, the net effect on the electricity price at the state or regional level will depend on the following two effects. ${ }^{23}$ First, the cost of supplying electricity

\footnotetext{
22 The remainder of this section focuses on comparing the BAU and CES scenarios. Supplemental figures showing regional electricity generation and capacity installations for alternative scenarios are available from authors upon request.

${ }^{23}$ This is partly based on the discussion in Paul et al. (2011).
} 
Table 7. Regional welfare impacts.

\begin{tabular}{|c|c|c|c|c|c|c|c|c|}
\hline \multirow[t]{2}{*}{ Region } & \multicolumn{2}{|c|}{ CES } & \multicolumn{2}{|c|}{ CAT_CES } & \multicolumn{2}{|c|}{ RES } & \multicolumn{2}{|c|}{ CAT_RES } \\
\hline & $\%$ & $\$$ & $\%$ & $\$$ & $\%$ & $\$$ & $\%$ & $\$$ \\
\hline South Central & -1.00 & -908 & -1.40 & -1272 & -0.70 & -628 & -0.77 & -700 \\
\hline Mountain & -0.57 & -530 & -0.78 & -734 & -0.25 & -232 & -0.42 & -394 \\
\hline South East & -0.52 & -499 & -0.25 & -228 & -0.28 & -260 & -0.08 & -71 \\
\hline Texas & -0.52 & -538 & -1.53 & -1614 & -0.36 & -386 & -0.84 & -876 \\
\hline North East & -0.37 & -420 & -0.06 & -61 & -0.13 & -146 & 0.04 & 46 \\
\hline North Central & -0.30 & -288 & -0.20 & -194 & -0.02 & -22 & -0.03 & -32 \\
\hline Florida & -0.29 & -247 & 0.20 & 169 & -0.25 & -206 & 0.18 & 147 \\
\hline Pacific & -0.24 & -236 & -0.02 & -9 & -0.05 & -50 & 0.06 & 64 \\
\hline New York & -0.22 & -282 & 0.54 & 694 & -0.11 & -140 & 0.42 & 538 \\
\hline New England & -0.16 & -188 & 0.54 & 616 & -0.06 & -66 & 0.41 & 468 \\
\hline California & -0.12 & -163 & 0.24 & 324 & 0.01 & 8 & 0.23 & 301 \\
\hline U.S. & -0.37 & -392 & -0.20 & -204 & -0.17 & -180 & -0.04 & -44 \\
\hline
\end{tabular}

Notes: Welfare impacts are population-weighted averages of net present value (NPV) of equivalent variation by household. "\$” refer to annual average of NPV welfare change per household expressed in 2006\$.

from any particular technology is affected by an implicit tax due to the cost of CES credits and, for qualifying technologies, an implicit subsidy from sales of CES credits. Second, the impact on electricity prices will depend on changes to the electricity supply curve. On the one hand, marginal generation costs will increase in regions that are heavily dependent on non-qualifying capacity as these will tend to experience significant capacity retirements shifting the supply curve to the left. On the other hand, regions that are endowed with rich, low-cost renewable resources will tend to experience significant investments driving down marginal cost to the extent that such technologies will enter the dispatch order at the front end; for high levels of renewable penetration, the CES will force deployment of renewable electricity generation at sites with relatively low capacity factors as the best site have already been used up, thus driving up marginal cost.

Regions that are more dependent on generation fuels that are not eligible under the CES, primarily coal, in general experience relatively large price increases. For example, North Central, South Central, South East, and the Mountain region experience significant reductions in the use of coal over the policy horizon and see the highest electricity price increases by 2050 . However, the regional ranking in terms of price increases varies over time with some regions experiencing modest price impacts before 2030 while showing substantial price increases by 2050 . For example, below-average price impacts in 2030 for NCENT and MOUNT reflect high-quality, low-cost wind resources in these regions implying - together with relatively small retirements in coal—only a small shift of the supply curve to the left and ensuing moderate marginal-cost increases. The relative moderate price increases for North Central for most years explains why this region suffers only from a modest NPV welfare loss although it experiences substantial 

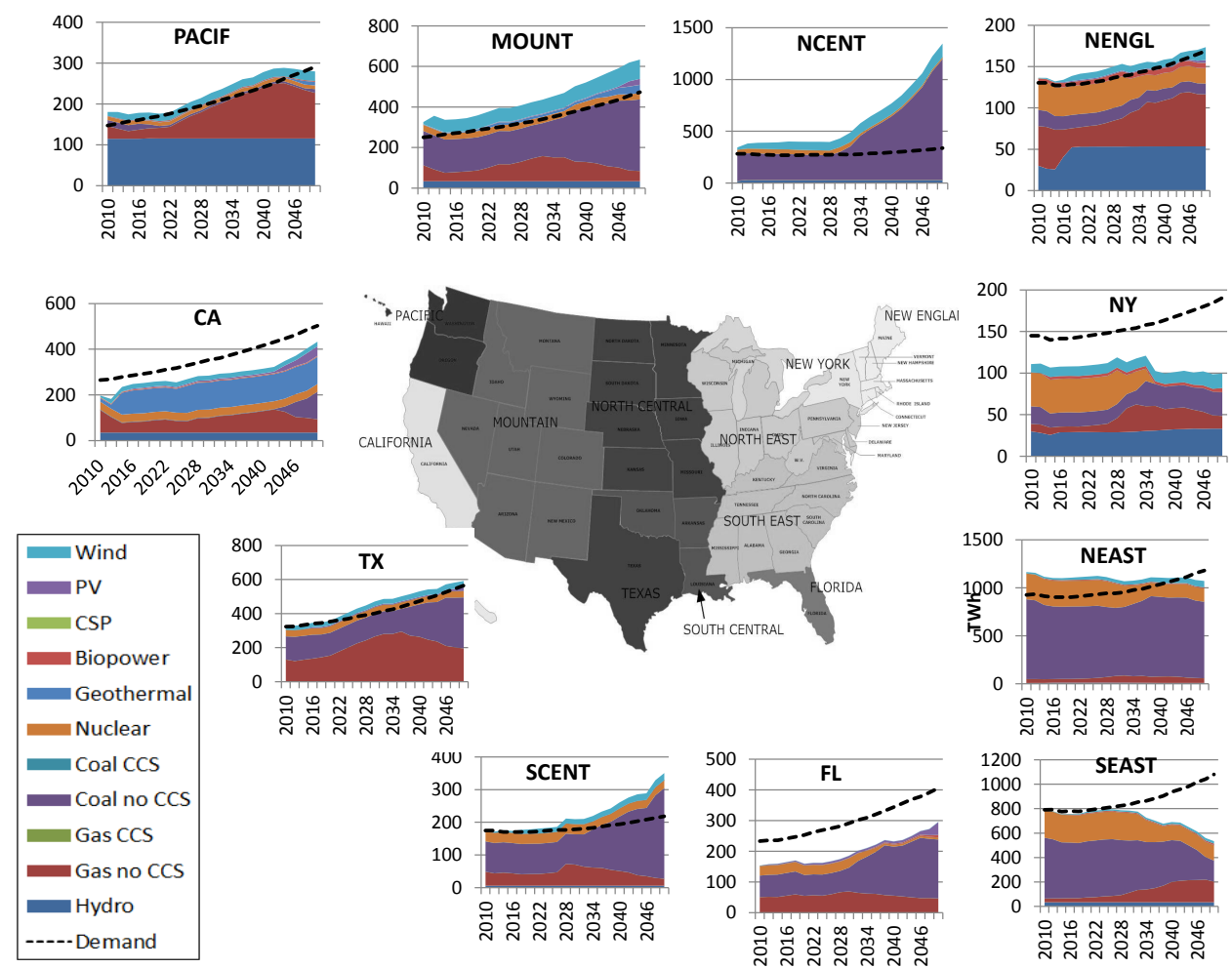

(a)
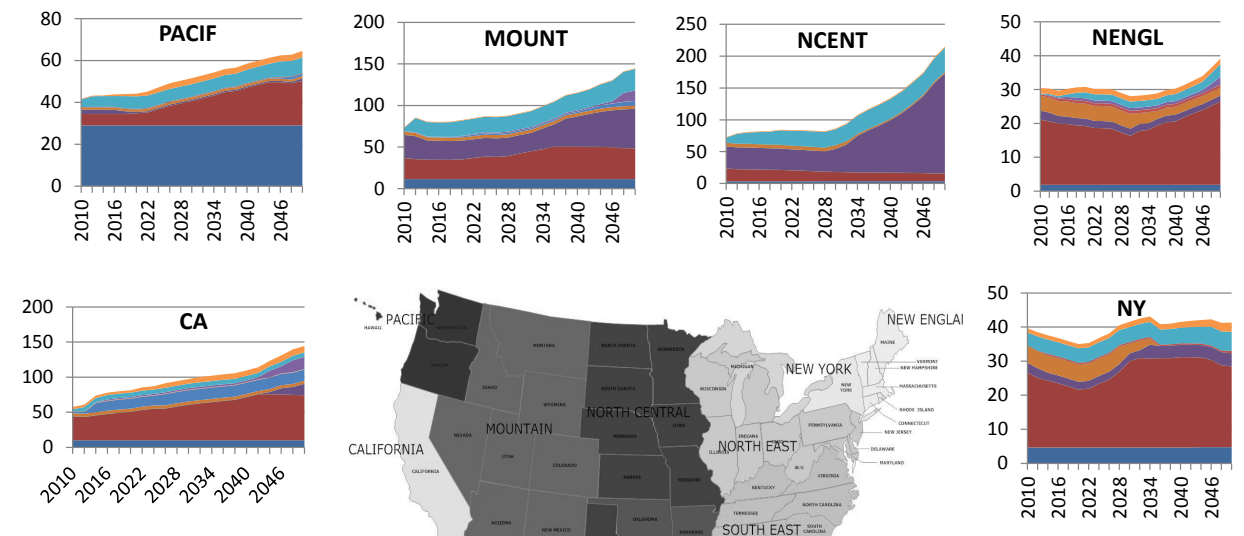

\begin{tabular}{|l|}
\hline Storage \\
Wind \\
$\square$ PV \\
$\square$ CSP \\
$\square$ Biopower \\
$\square$ Geothermal \\
$\square$ Nuclear \\
$\square$ Coal CCS \\
$\square$ Coal no CCS \\
$\square$ Gas CCS \\
$\square$ Gas no CCS \\
$\square$ Hydro
\end{tabular}
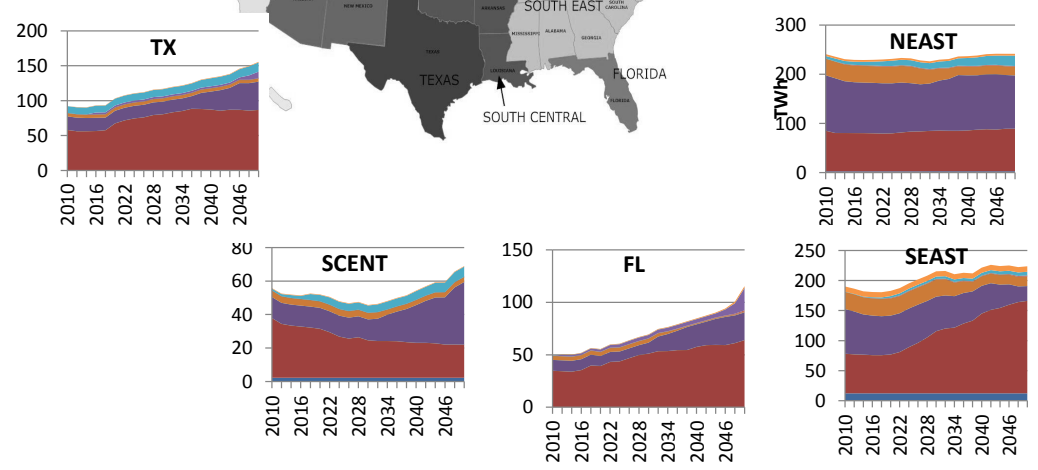

(b)

Figure 11. Regional electricity generation and demand in TWh (a) and installed capacity in GW (b) for BAU. 

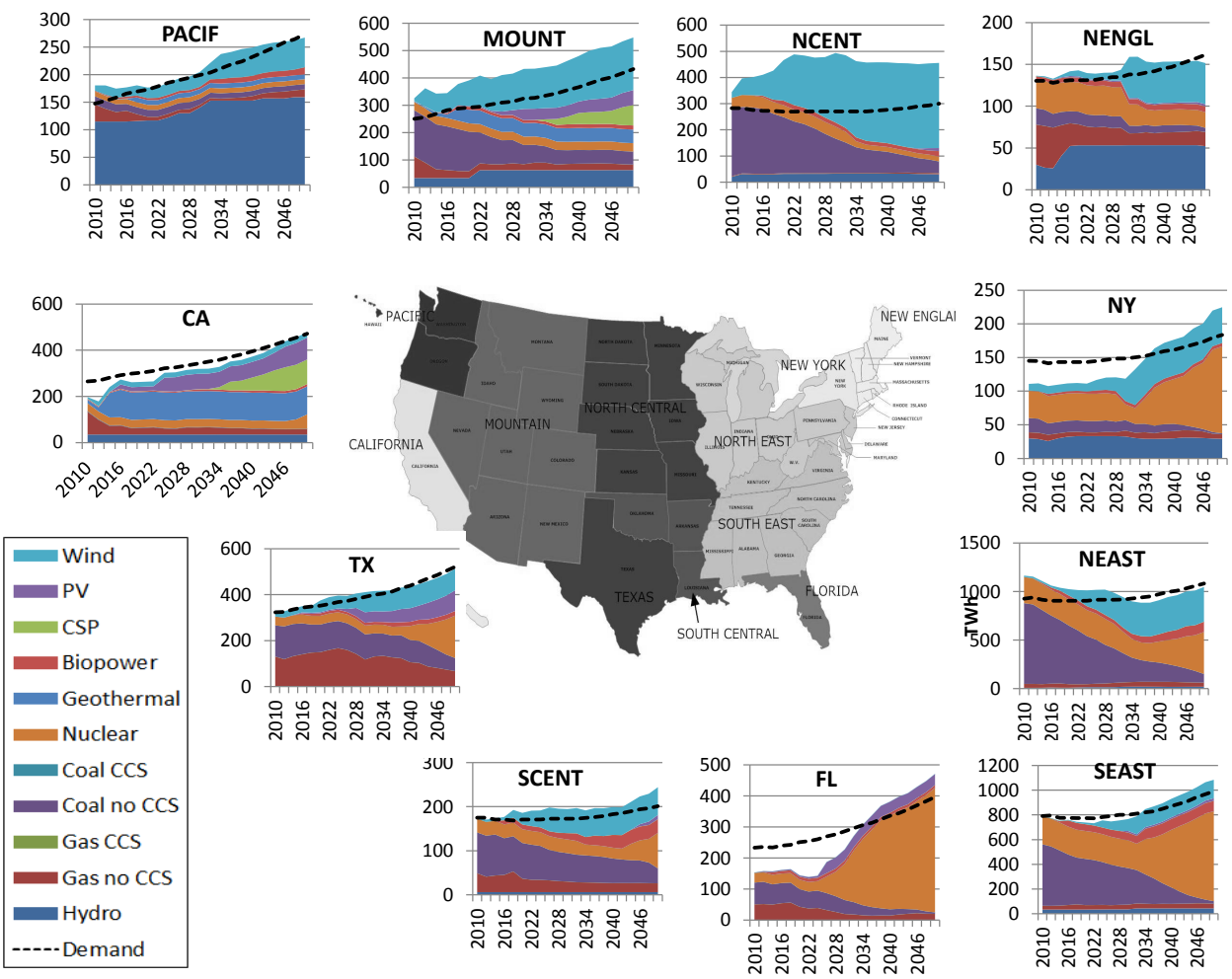

(a) Generation.
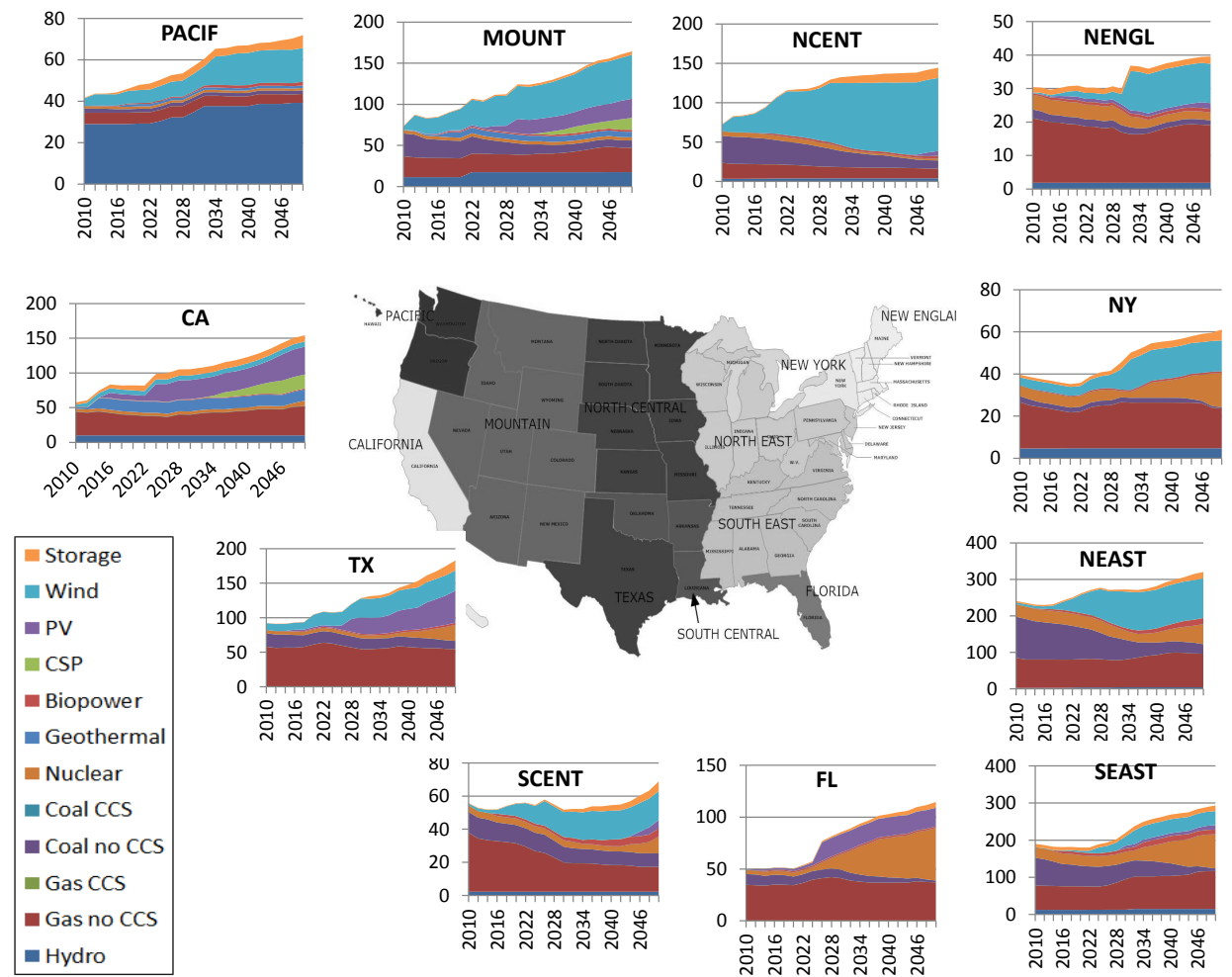

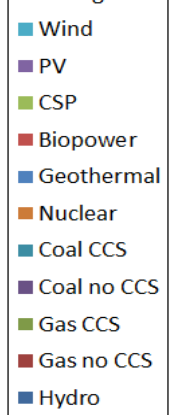
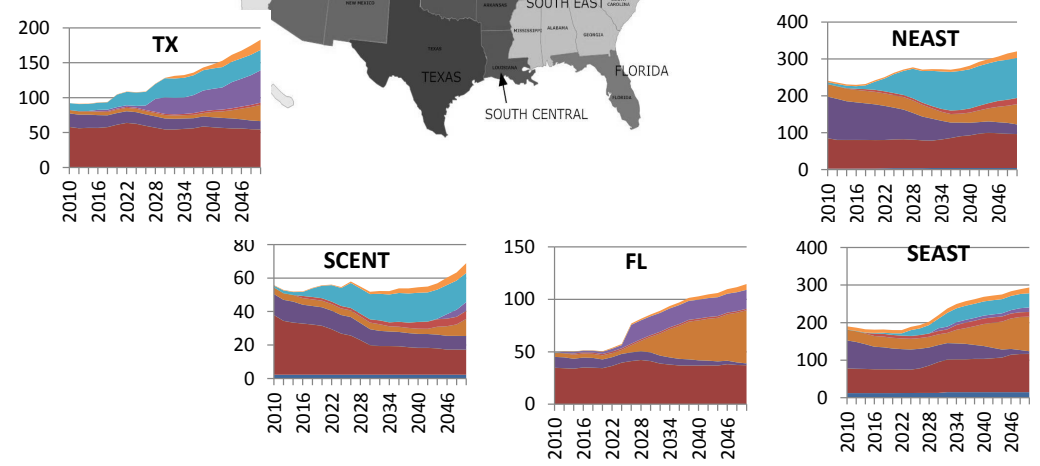

(b) Capacity.

Figure 12. Regional electricity generation and demand in TWh (a) and installed capacity in GW (b) for CES. 
Table 8. Regional electricity price impacts and inter-regional credit flows (CES scenario).

\begin{tabular}{|c|c|c|c|c|c|c|}
\hline \multirow{3}{*}{$\begin{array}{l}\text { Region } \\
\text { Year }\end{array}$} & \multicolumn{3}{|c|}{ Average retail price } & \multicolumn{3}{|c|}{ Inter-regional credit trading (billion $\$$ ) } \\
\hline & \multirow{2}{*}{$\begin{array}{r}\text { Cents/kWh } \\
2006\end{array}$} & \multicolumn{2}{|c|}{$\Delta \%$ from BAU } & \multirow{2}{*}{$\begin{array}{r}\text { Revenues } \\
2030\end{array}$} & \multirow{2}{*}{$\begin{array}{r}\text { Purchases } \\
2030\end{array}$} & \multirow{2}{*}{$\frac{\text { Net revenue }}{2030}$} \\
\hline & & 2030 & 2050 & & & \\
\hline North Central & 6.6 & 4.2 & 22.6 & 9.9 & 8.6 & 1.3 \\
\hline South Central & 7.6 & 10.3 & 21.0 & 3.2 & 4.9 & -1.7 \\
\hline South East & 7.1 & 7.8 & 16.2 & 12.4 & 20.4 & -8.0 \\
\hline Mountain & 7.0 & 1.3 & 15.7 & 9.6 & 5.3 & 4.4 \\
\hline North East & 8.6 & 5.3 & 15.5 & 16.7 & 24.5 & -7.8 \\
\hline Texas & 10.4 & 5.1 & 14.6 & 6.7 & 10.7 & -4.0 \\
\hline Pacific & 11.2 & 4.2 & 12.4 & 5.3 & 0.9 & 4.4 \\
\hline California & 12.9 & 5.8 & 10.7 & 8.3 & 1.1 & 7.1 \\
\hline New England & 13.6 & 4.9 & 7.2 & 3.3 & 1.6 & 1.7 \\
\hline New York & 15.3 & 4.0 & 5.3 & 2.7 & 1.3 & 1.4 \\
\hline Florida & 10.5 & 3.2 & 4.1 & 4.7 & 3.5 & 1.2 \\
\hline U.S. & 10.1 & 5.2 & 13.5 & 82.7 & 82.7 & 0 \\
\hline
\end{tabular}

reductions in the use of coal and large deployment of wind power. Regions with a relatively clean generation mix in the baseline and abundant hydro power and wind resources (Pacific), good offshore wind resources (New England), and large resource potentials for geothermal and solar power (California) show the smallest price increases in 2050 and bear the smallest economic burdens.

The regional distribution of generation does change somewhat but there are no big reversals in terms of regions changing their net trade position from being an net electricity exporter in the BAU to a net importer in the CES. In fact, the general pattern that emerges is one where regions that are net importers in the BAU—-such as California, New York, Florida, and South East-increase local generation in the CES and have to rely less on imports. This is to a large extent facilitated by the possibility to substantially increase local nuclear generation.

Table 8 shows that a federal CES policy induces sizable inter-regional capital transfers that occur in the market for CES credits. Given a CES target of around $71 \%$ by 2030 and an ensuing equilibrium credit price of 6.5 cents/kWh, the volume of traded credits in 2030 totals to $\$ 82.7$ billions. Regions with high capacity factors for renewables such as California, Mountain, and Pacific receive the largest net capital inflows from credit trading among all regions ranging from $\$ 4$ to 7 billions in 2030. By 2030, the South East and North East regions, currently heavily dependent on coal and nuclear, and Texas, currently dependent on coal and natural gas, are net importers of credits financing net capital gains in other regions. 
Table 9. Comparison of key results for a federal CES policy across different studies.

\begin{tabular}{lcccc}
\hline Variable & USREP-ReEDS & USREP $^{a}$ & Haiku (Paul et al., 2011) & EIA (2011) \\
\hline NPV welfare cost (trillion \$) & 1.97 & 2.08 & - & - \\
Cumulative $\mathrm{CO}_{2}$ emissions reductions (\%) & 17 & 11 & - & - \\
$2012-2050$ & 24 & 20 & 24 & 28 \\
$2015-2030$ & 5.4 & 7.4 & 11.3 & 18.3 \\
Electricity price impacts (\%) & 13.5 & 10.0 & - & - \\
$\quad$ Year 2030 & 906 & 1,194 & 900 & 301 \\
Year 2050 & & & \\
Wind generation in 2035 (TWh) &
\end{tabular}

Notes: ${ }^{a}$ USREP model with “top-down” representation of electricity sector (Rausch and Karplus, 2012).

\subsection{Comparison of Results with Other Studies}

Table 9 provides a comparison of our results with similar studies that have investigated a federal CES policy for electricity (with approximately similar specifications of the policy instrument). We first compare our results to a study that uses a version of the USREP model which represents the electricity sector in a "top-down" manner employing nested CES production functions (Rausch and Karplus, 2012). Rausch and Karplus (2012) describe the "top-down" model for electricity and how large-scale intermittent wind generation and regional wind resources are introduced in a pure "top-down" CGE framework.

As is evident from Table 9, the "top-down" approach yields largely similar results in terms of NPV welfare cost, electricity price impacts, and wind generation as compared to the USREP-ReEDS model that features a detailed "bottom-up" formulation of the electricity sector. The slightly larger cumulative $\mathrm{CO}_{2}$ emissions reductions obtained from the USREP-ReEDS model are due to the fact that the share of nuclear power in total electricity generation is somewhat higher reflecting different cost assumptions across the models. Estimates of wind generation across both modeling approaches are roughly similar, with the USREP-ReEDS model projecting that wind electricity is 190 TWh smaller by 2035 compared to the USREP "top-down" model. Note that the "top-down" USREP model does only include wind in terms of renewable energy sources, whereas the USREP-ReEDS model comprises all major renewable energy technologies. Rausch and Karplus (2012) carry out a more detailed comparison of both approaches and find estimates for wind electricity obtained from the "top-down" USREP model are very close to the sum of electricity generated from all non-hydro renewables in the USREP-ReEDS model.

The results from both versions of the USREP model are close to results obtained from the Haiku model (Paul et al., 2011). The Haiku model projects slightly higher electricity prices by 2030 as it includes average cost pricing in regions that are subject to cost-of-service regulation whereas both USREP models assume marginal cost pricing in all regions. The NEMS model (Energy Information Administration, 2011) projects higher electricity prices by 2030, consistent with a more pessimistic view on the amount of wind energy that would be deployed under such a 
policy.

\section{CONCLUSIONS}

This paper considered the distributional and efficiency impacts of clean and renewable energy standards for electricity. While our analysis focused on the U.S., some of the conclusions may be applicable in the context of other countries. Our analysis employed an integrated modeling framework linking a global model of economic activity and energy systems with an electricity generation dispatch and capacity expansion model for the contiguous U.S.

We find that a CES policy, broadly consistent with the proposal by the Obama administration, and a RES policy, mandating that $70 \%$ of electricity generated in 2050 has to come from renewable energy sources, would have significant effects on electricity sector $\mathrm{CO}_{2}$ emissions. Cumulative $\mathrm{CO}_{2}$ emissions in the electricity sector between 2012 and 2050 will be reduced by roughly $51 \%$ in the CES and by $33 \%$ in the RES case relative to a no-policy baseline. These reductions correspond to a cut of 17 and $11 \%$ in terms of economy-wide cumulative emissions for the CES and RES scenario, respectively. The CES and RES lead to extensive retirements of coal-fired capacity and substantial deployment of wind power. Besides significant additions in wind power, some regions show substantial investments in PV capacity (California, Texas, and Mountain region), CSP (California and Mountain region), and geothermal (California). In regions without abundant renewable energy resources that are subject to increasing costs with the expansion of electricity generation from renewable sources, nuclear power is the economically preferred approach to meeting the standard (Florida, South East, and New York).

We estimate that the CES policy modeled here is about twice as costly than a comprehensive market-based carbon pricing policy—such as a federal cap-and-trade regulation or a carbon tax-that achieves the same year-on-year emissions reductions. The RES policy considered here is four times more costly as it focuses on a smaller set of technologies, in particular it does not allow for "clean" gas and nuclear power to play a role in meeting the standard's target. These estimates are best viewed as providing a lower bound on the efficiency costs of CES and RES policies. If banking and borrowing of emissions permits under a cap-and-trade program were allowed, if emissions reductions could be achieved from non- $\mathrm{CO}_{2}$ greenhouse gases, or if the carbon revenue was used to lower distortionary taxes, the CES and RES policies would compare even less favorably in terms of efficiency costs.

Clean and energy standards in the electricity sector are regressive, i.e. they place a disproportionably large burden on low-income households who spend a larger fraction of the income on electricity relative to high-income households. Regional differences in welfare impacts are driven by the variation in regional electricity price impacts. The general pattern is one where regions with low cost electricity because they rely extensively on low cost coal generation see the largest electricity price increases. However, even with larger percentage increases electricity prices generally remain considerable lower in these regions than in others with higher current electricity prices. Regions with abundant hydro power and wind resources (Northwestern and New England states), with large potentials for geothermal and solar power (California) and a relatively clean generation mix in the baseline experience the smallest price increases and bear the 
smallest burden of economic costs.

The sizable distributional effects under clean and renewable energy standards in terms of household impacts by region and income can be problematic as these policies do not generate any revenue that could be used to alter unintended distributional outcomes of the policy. The revenue-neutral nature of credit trading means that the revenue from selling clean energy credits to dirty electricity generators is used to subsidize electricity production at clean generators. In contrast, electricity prices under a cap-and-trade ${ }^{24}$ or carbon tax policy fully reflect the carbon price signal, and generate carbon revenue that is available to address distributional issues of greenhouse gas policy. Assuming that the carbon revenue is recycled using equal per-capita lump-sum transfer payments, we find that such carbon pricing policies would be progressive. ${ }^{25}$.

The results are derived in a model where the electricity sector is represented as if all regions operated under a competitive market structure. While average cost pricing for regions with cost-of-service regulation will not change the efficiency results of our analysis - assuming a federal cap-and-trade policy is designed such that consumers of regulated utilities fully perceive the carbon price signal - it may alter the distributional outcome of both technology mandates and carbon pricing policies considered here. Further sensitivity analyses would also need to explore the implications of varying technology cost assumptions, in particular with respect to renewable technologies and carbon capture and sequestration options, as well as limiting the future availability of nuclear power.

\section{Acknowledgements}

The authors acknowledge the support of the Joint Institute for Strategic Energy Analysis, which is operated by the Alliance for Sustainable Energy, LLC, on behalf of the U.S. Department of Energy's National Renewable Energy Laboratory, the University of Colorado-Boulder, the Colorado School of Mines, the Colorado State University, the Massachusetts Institute of Technology, and Stanford University under grant NREL 6A502020 "Integration of a Computable General Equilibrium Model with an Electricity Sector Optimization Model to Assess the Economic Impacts of U.S. Climate Policy". We further acknowledge support of the MIT Joint Program on the Science and Policy of Global Change through a combination of government, industry, and foundation funding, the MIT Energy Initiative, and additional support for this work from a coalition of industrial sponsors (for a complete list see:

http://globalchange.mit.edu/sponsors/all). We would like to thank Doug Arent, Henry Chen, John Reilly, and Walter Short for helpful comments and discussion.

\section{REFERENCES}

Aldy, J. E., 2011: Promoting Clean Energy in the American Power Sector. Hamilton Project Discussion Paper 2011-04. Brookings Institution, Washington, D.C.

Armington, P., 1969: A Theory of Demand for Products Distinguished by Place of Production.

${ }^{24}$ Assuming emissions permits are fully auctioned or the opportunity costs of free permits allocated to price-regulated utilities are fully passed through to consumers.

${ }^{25}$ This is not a novel result and is in line with other studies. See, for example, Bento et al. (2009) and Rausch et al. (2010). 
International Monetary Fund Staff Papers, 16: 159-76.

Atkinson, A. B. and J. E. Stiglitz, 1980: Lectures on Public Economics. McGraw-Hill, New York.

Ballard, C., 2000: How Many Hours Are in a Simulated Day? The Effect of Time Endowment on the Results of Tax-policy Simulation Models. Working Paper, Michigan State University.

Bento, A. M., L. H. Goulder, M. R. Jacobsen and R. H. von Haefen, 2009: Distributional and Efficiency Impacts of Increased US Gasoline Taxes. American Economic Review, 99: 1-37.

Böhringer, C. and T. F. Rutherford, 2008: Combining Bottom-up and Top-down. Energy Economics, 30(2): 574-596.

Böhringer, C. and T. F. Rutherford, 2009: Integrated Assessment of Energy Policies: Decomposing Top-down and Bottom-up. Journal of Economic Dynamics and Control, 33: 1648-1661.

Burtraw, D., K. Palmer, R. Bharvirkar and A. Paul, 2001: The Effect of Allowance Allocation on the Cost of Carbon Emission Trading. Resources For the Future Discussion Paper.

Caron, J. and S. Rausch, 2011: State-level U.S. and International Trade: Dataset and Model. Unpublished manuscript, MIT JPSPGC.

Dirkse, S. P. and M. C. Ferris, 1995: The PATH Solver: a Non-monontone Stabilization Scheme for Mixed Complementarity Problems. Optimization Methods and Software, 5: 123-156.

DSIRE, 2011: Database of State Incentives for Renewables \& Efficiency .

Dyni, J. R., 2006: Geology and Resources of Some World Oil-Shale Deposits. USGS Scientific Investigations Report 2005-5294, p. 42.

Energy Information Administration, 2007: Energy Market Impacts of a Clean Energy Portfolio Standard-Follow-up.

Energy Information Administration, 2009a: Impacts of a 25-Percent Renewable Electricity Standard as Proposed in the American Clean Energy and Security Act Discussion Draft.

Energy Information Administration, 2009b: The National Energy Modeling System: An Overview.

Energy Information Administration, 2009c: State Energy Data System. Washington, D.C.

Energy Information Administration, 2011: Analysis of Impacts of a Clean Energy Standard. (http://democrats.science.house.gov/sites/democrats.science.house.gov/files/shortlink.pdf).

Feenberg, D. and E. Coutts, 1993: An Introduction to the TAXSIM Model. Journal of Policy Analysis and Management, 12(1).

Fullerton, D. and G. Heutel, 2007: The General Equilibrium Incidence of Environmental Taxes. Journal of Public Economics, 91: 571-591.

GTAP, G., 2008: Global Trade, Assistance, and Production: The GTAP 7 Data Base. Center for Global Trade Analysis, Purdue University. 
Holland, S. P., J. E. Hughes and C. R. Knittel, 2009: Greenhouse Gas Reductions under Low Carbon Fuel Standards? American Economic Journal: Economic Policy, 1(1): 106-146.

Hourcade, J., M. Jaccard, C. Bataille and F. Ghersi, 2006: Hybrid Modeling: New Answers to Old Challenges Introduction to the Special Issue of The Energy Journal. Energy Journal, 27(special issue).

IMPLAN, M., 2008: State-Level U.S. Data for 2006. Stillwater, MN: Minnesota IMPLAN Group.

Langnissa, O. and R. Wise, 2003: The Renewables Portfolio Standard in Texas: An Early Assessment. Energy Policy, 31: 527-535.

Lanz, B. and S. Rausch, 2011: General Equilibrium, Electricity Generation Technologies and the Cost of Carbon Abatement: A Structural Sensitivity Analysis. Energy Economics, 33: 1035-1047.

Lindall, S., D. Olson and G. Alward, 2006: Deriving Multi-Regional Models Using the IMPLAN National Trade Flows Model. Paper delivered at the 1998 Regional Science Association International meeting in Sante Fe, New Mexico, 36(1): 76-83.

Mathiesen, L., 1985: Computation of Economic Equilibria by a Sequence of Linear Complementarity Problems. Mathematical Programming Study, 23: 144-162.

Metcalf, G. E., 2009: Market-based Policy Options to Control U.S. Greenhouse Gas Emissions. Journal of Economic Perspectives, 23: 5-27.

Morris, J. F., J. M. Reilly and S. Paltsev, 2010: Combining a Renewable Portfolio Standard with a Cap-and-Trade Policy: A General Equilibrium Analysis. MIT JPSPGC, Report 187, July, 19 p. (http://globalchange.mit.edu/files/document/MITJPSPGC_Rpt187.pdf).

National Renewable Energy Laboratory: Eastern Wind Integration and Transmission Study (EWITS).

National Renewable Energy Laboratory, 2010: Solar Advisor Model (SAM) version 2010.4.12. (https://www.nrel.gov/analysis/sam/).

Oakridge National Laboratories, 2009: Estimated Annual Cumulative Biomass Resources Available by State and Price. (http://bioenergy.ornl.gov/main.aspx\#Biomass\%20Resources).

Palmer, K. and D. Burtraw, 2005: Cost-effectiveness of Renewable Electricity Policies. Energy Economics, 27: 873-894.

Palmer, K., R. Sweeney and M. Allaire, 2010: Modeling Policies to Promote Renewable and Low-Carbon Sources of Electricity. RFF Backgrounder.

Palmer, K., A. Paul, M. Woerman and D. C. Steinberg, 2011a: Federal Policies for Renewable Electricity: Impacts and Interactions. Energy Policy, 39: 3975-3991.

Palmer, K., R. Sweeney and M. Allaire, 2011b: Clean Energy Standards for Electricity: Policy Design Implications for Emissions, Supply, Prices, and Regions. RFF Discussion Paper $11-35$. 
Paltsev, S., J. M. Reilly, H. Jacoby, R. Eckhaus, J. McFarland, M. Sarofim, M. Asadoorian and M. Babiker, 2005: The MIT Emissions Prediction and Policy Analysis (EPPA) Model: Version 4. MIT JPSPGC, Report 125, August, 72 p. (http://globalchange.mit.edu/files/document/MITJPSPGC_Rpt125.pdf).

Parry, I. W. and R. C. Williams III, 2011: Moving U.S. Climate Policy Forward: Are Carbon Taxes the Only Good Alternative? RFF Discussion Paper 11-02.

Paul, A., K. Palmer and M. Woerman, 2011: Modeling a Clean Energy Standard for Electricity: Policy Design Implications for Emissions, Supply, Prices, and Regions. RFF Discussion Paper 11-35.

Rausch, S. and V. J. Karplus, 2012: Markets versus Regulation: The Efficiency and Distributional Impacts of U.S. Climate Policy Proposals. MIT JPSPGC, Report, forthcoming.

Rausch, S. and T. F. Rutherford, 2009: Tools for Building National Economic Models Using State-Level Implan Social Accounts. Cambridge, Massachusetts, MIT, mimeo.

Rausch, S., G. E. Metcalf, J. M. Reilly and S. Paltsev, 2010: Distributional Implications of Alternative U.S. Greenhouse Gas ControlMeasures. The B.E. Journal of Economic Analysis \& Policy, 10(2).

Rausch, S., G. E. Metcalf and J. M. Reilly, 2011a: Distributional Impacts of Carbon Pricing: A General Equilibrium Approach with Micro-Data for Households. Energy Economics, 33: S20-S33.

Rausch, S., G. E. Metcalf, J. M. Reilly and S. Paltsev, 2011b: Distributional Impacts of a U.S. Greenhouse Gas Policy: a General Equilibrium Analysis of Carbon Pricing.

Rutherford, T. F., 1995: Extension of GAMS for Complementarity Problems arising in Applied Economics. Journal of Economic Dynamics and Control, 19(8): 1299-1324.

Rutherford, T. F., 1999: Applied General Equilibrium Modeling with MPSGE as a GAMS Subsystem: an Overview of the Modeling Framework and Syntax. Computational Economics, 14: 1-46.

Short, W., N. Blair, P. Sullivan and T. Mai, 2009: ReEDS Model Documentation: Base Case Data and Model Description. National Reneweable Energy Laboratory. (http://www.nrel.gov/analysis/reeds/pdfs/reeds_full_report.pdf).

Stavins, R. N., 2008: A Meaningful U.S. Cap-and-Trade System to Address Climate Change. Harvard Environmental Law Review, 32: 293-371.

Sugandha, T. D., M. Yuan, P. Bernstein, W. D. Montgomery and A. Smith, 2009: A Top-down Bottom-up Modeling Approach to Climate Change Policy Analysis. Energy Economics, 31: S223-S234.

Sullivan, P., J. Logan, L. Bird and W. Short, 2009: Comparative Analysis of Three Proposed Federal Renewable Electricity Standards. National Renewable Energy Laboratory, Technical Report NREL/TP-6A2-45877.

United Nations, 2000: World Population Prospects: The 2000 Revision. Population Division, Department of Economic and Social Affairs. 
United Nations, 2001: Long-run World Population Projections: Based on the 1998 Revision. United Nations: New York.

U.S. Census Bureau, 2000: U.S. Population Projections: State Interim Population Projections by Age and Sex: 2004 - 2030.

(http://www.census.gov/population/www/projections/projectionsagesex.html).

U.S. Census Bureau, 2010: Foreign Trade Statistics State Data Series: Origin of Movement and State of Destination Data Series.

US Department of Energy, 2009: U.S. Crude Oil, Natural Gas, and Natural Gas Liquids Reserves, 1977 through 2007. Annual Reports, DOE/EIA-0216.

US Geological Survey, 2009: USCOAL Coal Resources Database.

(http://energy.er.usgs.gov/coalres.htm and http://pubs.er.usgs.gov/djvu/B/bull_1412.djvu).

Ventyx, 2006: Annual Capacity Factors for Hydropower. (http://www.ventyx.com/).

Wilcox, S. and W. Marion, 2008: User Manual for TMY3 Data Sets. National Renewable Energy Laboratory. NREL/TP-581-43156. Golden, CO.

Wiser, R., C. Namovicz, M. Gielecki and R. Smith, 2007: The Experience with Renewable Portfolio Standards in the United States. Electricity Journal, 20(4): 8-20. 


\section{APPENDIX A: ReEDS Model}

This section describes - in simplified form - the variables, constraints, and other attributes of the linear program formulation of ReEDS for a single year. ReEDS minimized overall electric system costs while meeting all of the constraints of the system including new generation capacity, time-slice-dependent electricity generation and transmission capacity. These costs represent the 20 year present value of a stream of costs. After each modeled year's solve, ReEDS updates values, for example existing capacity of each technology and costs of performances of new technologies, and continues on to the next year's solve. Variables are denoted by upper case symbols and are defined in Table A1. The major decision variables include capacity of conventionals, renewables, and storage along with transmission; and dispatch of conventional capacity and storage. Lower case symbols denote parameters and are defined in Table A2. In the following equations, "existing" or "old" refers to technologies or transmission that are already in existence at the time of the current year, and "new" refers to potential new technology or transmission builds.

Table A1. Sets and variables in ReEDS model.

\begin{tabular}{ll}
\hline Sets & Regions \\
$s$ & Regions neighboring region $s$ \\
$r$ & Time slice \\
$z$ & Technologies for electricity generation and storage \\
$g$ & Dispatchable technologies \\
$d \in g$ & Non-dispatchable technologies \\
$n \in g$ & Old and new technologies or transmission capacity \\
$q=\{o, n\}$ & Demand bins used to approximate the demand curve as piecewise constant \\
$b$ & \\
& \\
Variables & Average electricity generation from new ( $q=n$ ) and existing ( $q=o$ ) technologies in \\
$Y_{g, s, z}^{q}$ & region $s$ in time slice $z$ (in MW) \\
$P_{s, b}$ & Price (in $\$$ MW) \\
$C_{g, s}^{q}$ & New $(q=n)$ and existing $(q=o)$ electricity generation capacity of technology $g$ in \\
& region $s$ (in MW) \\
$T_{s, r, z}$ & Average net electricity transmitted from region $s$ to neighboring region $r$ in time slice $z$ \\
$D_{s, z, b}$ & Electricity demand increments in demand bin $b$ for time slice $z$ in region $s$ (in MW) \\
$R_{s, z}$ & Operating reserve margin requirement in region $s$ in time slice $z$ (in MW) \\
$K_{s, r}^{q}$ & Newly built $(q=n$ ) and existing $(q=o$ ) transmission capacity between region \\
& $s$ and $r$ (in MW) \\
$S_{d, s, z}^{q}$ & Generation capacity from new $(q=n)$ and existing $(q=o$ ) dispatchable technologies \\
& committed to providing operating reserves in region $s$ in time slice $z$ (in MW) \\
\hline &
\end{tabular}

The objective is to minimize total system costs comprising fixed costs for new electricity generation technologies, variable costs for all technologies, and transmission costs for new 
transmission builds subject to a number of constraints:

$$
\min _{Y_{g, s, z}^{q}, P_{s, b}, C_{g, s}^{q}, T_{s, r, z}, D_{s, z, b}, R_{s, z}, K_{s, r}^{q}, S_{d, s, z}^{q}} \sum_{g, s} C_{g, s} n_{g, s}+\sum_{q, g, s, z} Y_{g, s, z}^{q}\left(l_{g}^{q}+e_{g, s}\right) h_{z}+\sum_{s, r} K_{s, r}^{n} w_{s, r}
$$

subject to (1) Generation from all technologies plus imports minus exports must be greater than demand:

$$
\sum_{q, g \in d} Y_{g, s, z}^{q}+\sum_{q, g \in n} C_{g, s}^{q} f_{g, s, z}^{q}+\sum_{r} T_{r, s, z} \geq \sum_{b} D_{s, z, b} \quad \forall s, z
$$

(2) Planning reserves (capacity provided by all technologies plus capacity imports minus capacity exports must be greater than the planning reserve margin times peak demand. Dispatchable technologies contribute full nameplate capacity toward firm capacity, whereas non-dispatchable technologies contribute only a fraction of nameplate capacity, i.e. the capacity value).:

$$
\sum_{q, g \in d} C_{g, s}^{q}+\sum_{q, g \in n} C_{g, s}^{q} v_{g, s, z}^{q}+\sum_{r} K_{r, s}^{n} \geq \sum_{b} D_{s, z, b} p_{s} m_{s} \quad \forall s, z
$$

(3) Operating reserves provided by all technologies must exceed the operating reserve requirements:

$$
\sum_{q, g \in d} S_{g, s, z}^{q} \geq R_{s, z} \quad \forall s, z
$$

(4) Existing and new dispatchable electricity generators in each region and time-slice must divide their electricity generation capacity into either providing electricity generation or providing operating reserves. In ReEDS, there are additional restrictions on the ability of dispatchable generators to provide operating reserves, depending on the level of flexibility of those generators:

$$
C_{g, s, z}^{q} \geq Y_{g, s, z}^{q}+S_{g, s, z}^{q} \quad \forall s, z, q, g \in d
$$

(5) Installed existing and new transmission capacity must exceed the power that is transferred between regions in each time-slice:

$$
\sum_{q} K_{s, r}^{q} \geq T_{s, r, z} \quad \forall s, r, z
$$

(6) Installed existing and new transmission capacity must exceed the capacity that is contracted between regions. These capacity contracts are annual, i.e. they do not depend on the time slice:

$$
\sum_{q} K_{s, r}^{q} \geq K_{s, r}^{o} \quad \forall s, r
$$

Additional features in ReEDS, not shown here, include minimum loading requirements and planned and forced outages for dispatchable technologies, curtailment from renewable and must-run technologies, different types of operating reserves, renewable supply curves and 
Table A2. Parameters in ReEDS model.

\begin{tabular}{|c|c|}
\hline$c_{g, s}$ & $\begin{array}{l}\text { Generation capacity of technology } g \text { in region } s \text { that is already in existence at beginning } \\
\text { of period (in MW) }\end{array}$ \\
\hline$f_{n, s, z}^{q}$ & $\begin{array}{l}\text { Average capacity factor for new }(q=n) \text { and existing }(q=o) \text { non-dispatchable technology } \\
n \text { in time slice } z \text { in region } s\end{array}$ \\
\hline$v_{n, s, z}^{q}$ & $\begin{array}{l}\text { Average capacity value of new }(q=n) \text { and existing }(q=o) \text { capacity for non-dispatchable } \\
\text { technology } n \text { in time slice } z \text { in region } s\end{array}$ \\
\hline$p_{s}$ & $\begin{array}{l}\text { Multiplier on average electricity demand to approximate peak simultaneous electricity } \\
\text { demand in time slice } z \text { in region } s\end{array}$ \\
\hline$m_{s}$ & Planning reserve margin in region $s$ \\
\hline$t_{s, r}$ & Existing transmission capacity connecting region $s$ to neighboring region $r$ (in $\mathrm{MW}$ ) \\
\hline$n_{g, s}$ & $\begin{array}{l}\text { Fixed costs associated with potential new electricity generation capacity of technology } \\
g \text { in each time slice } z \text {. This includes capital costs as well as fixed operation and } \\
\text { maintenance costs (in } \$ / \mathrm{MW} \text { ) }\end{array}$ \\
\hline$l_{g}^{q}$ & $\begin{array}{l}\text { Variable costs associated with electricity generation from new }(q=n) \text { and existing }(q=o) \\
\text { capacity. This includes variable operation and maintenance costs (in } \$ / \mathrm{MWh})\end{array}$ \\
\hline$e_{g, s}$ & $\begin{array}{l}\text { Cost of fuel associated with electricity generation from technology } g \text { in region } s \text {. } \\
\text { Fuel costs depend on technology-specific heat rates and regional fuel prices (in } \$ / M W h \text { ). }\end{array}$ \\
\hline$h_{z}$ & Number of hours contained in time slice $z$ \\
\hline$w_{s, r}$ & $\begin{array}{l}\text { Cost of new transmission connecting region } s \text { to region } r \text {. This depends on regional } \\
\text { differences in cost of transmission and differences in the distances between } \\
\text { center-points of the regions (in } \$ / \mathrm{MW} \text { ). }\end{array}$ \\
\hline
\end{tabular}

resource constraints, and contracts of variable renewable power. In addition, this representation does not show the (non-linear) statistical calculations that occur between the model year solves.

In addition to technology-specific parameters such as the supply curves for renewable energy resources discussed above, technologies in ReEDS are characterized generally by the cost and performance parameters summarized in Table A4.

Incorporating a demand response in ReEDS required modifying the objective function. Instead of minimizing total system costs, as is the case for the native ReEDS model, the integrated model chooses generation, transmission, and capacity decisions for each two-year period in the electric sector that maximize the sum of regional consumer and producer surpluses. Eq. (17) is thus replaced by:

$$
\max \underbrace{\sum_{s, z, b} D_{s, z, b} h_{z} P_{s, b}}_{\int \text { under demand curve }}-\underbrace{\left\{\sum_{g, s} C_{g, s} n_{g, s}+\sum_{q, g, s, z} Y_{g, s, z}^{q}\left(l_{g}^{q}+e_{g, s}\right) h_{z}+\sum_{s, r} K_{s, r}^{n} w_{s, r}\right\}}_{\int \text { under supply curve }} .
$$


Table A3. Time slice definitions.

\begin{tabular}{llllr}
\hline Time Slice & $\begin{array}{l}\text { Number of } \\
\text { Hours/Year }\end{array}$ & Season & Time of Day & Time Period \\
\hline H1 & 736 & Summer & Night & 10:00pm-6:00am \\
H2 & 644 & Summer & Morning & $6: 00 \mathrm{am}-1: 00 \mathrm{pm}$ \\
H3 & 328 & Summer & Afternoon & $1: 00 \mathrm{pm}-5: 00 \mathrm{pm}$ \\
H4 & 460 & Summer & Evening & $5: 00 \mathrm{pm}-10: 00 \mathrm{pm}$ \\
H5 & 488 & Fall & Night & $10: 00 \mathrm{pm}-6: 00 \mathrm{am}$ \\
H6 & 427 & Fall & Morning & $6: 00 \mathrm{am}-1: 00 \mathrm{pm}$ \\
H7 & 244 & Fall & Afternoon & $1: 00 \mathrm{pm}-5: 00 \mathrm{pm}$ \\
H8 & 305 & Fall & Evening & $5: 00 \mathrm{pm}-10: 00 \mathrm{pm}$ \\
H9 & 960 & Winter & Night & $10: 00 \mathrm{pm}-6: 00 \mathrm{am}$ \\
H10 & 840 & Winter & Morning & $6: 00 \mathrm{am}-1: 00 \mathrm{pm}$ \\
H11 & 480 & Winter & Afternoon & $1: 00 \mathrm{pm}-5: 00 \mathrm{pm}$ \\
H12 & 600 & Winter & Evening & $5: 00 \mathrm{pm}-10: 00 \mathrm{pm}$ \\
H13 & 736 & Spring & Night & $10: 00 \mathrm{pm}-6: 00 \mathrm{am}$ \\
H14 & 644 & Spring & Morning & $6: 00 \mathrm{am}-1: 00 \mathrm{pm}$ \\
H15 & 368 & Spring & Afternoon & $1: 00 \mathrm{pm}-5: 00 \mathrm{pm}$ \\
H16 & 460 & Spring & Evening & $5: 00 \mathrm{pm}-10: 00 \mathrm{pm}$ \\
H17 & 40 & Summer & Peak & \\
& & & & 40 highest demand hours of \\
\end{tabular}

Table A4. Cost and performance parameters in ReEDS model.

Capital cost $(\$ / \mathrm{MW})$

Fixed and variable operating costs $(\$ / \mathrm{MWh})$

Fuel costs $(\$ / M M B t u)$ for applicable plants

Construction period (years)

Equipment lifetime (years)

Financing costs (such as nominal interest rate, loan period, debt fraction etc.)

Tax credits (investment or production)

Heat rate (MMBtu/MWh) for fuel-consuming plants

Capacity factor for wind and solar plants

Round trip efficiency for storage technologies

Planned and unplanned outage rates $(\%)$ for dispatchable plants

Minimum turndown ratio (\%) for dispatchable plants

Daily cycling penalties for coal plants

Quick-start and spinning reserve capability for plants that provide operating reserves

Emissions levels of carbon, sulfur dioxide, nitrogen oxides and mercury 
FOR THE COMPLETE LIST OF JOINT PROGRAM REPORTS: http://globalchange.mit.edu/pubs/all-reports.php

181. Development of a Fast and Detailed Model of Urban-Scale Chemical and Physical Processing Cohen \& Prinn October 2009

182. Distributional Impacts of a U.S. Greenhouse Gas Policy: A General Equilibrium Analysis of Carbon Pricing Rausch et al. November 2009

183. Canada's Bitumen Industry Under $\mathrm{CO}_{2}$ Constraints Chan et al. January 2010

184. Will Border Carbon Adjustments Work? Winchester et al. February 2010

185. Distributional Implications of Alternative U.S. Greenhouse Gas Control Measures Rausch et al. June 2010

186. The Future of U.S. Natural Gas Production, Use, and Trade Paltsev et al. June 2010

187. Combining a Renewable Portfolio Standard with a Cap-and-Trade Policy: A General Equilibrium Analysis Morris et al. July 2010

188. On the Correlation between Forcing and Climate Sensitivity Sokolov August 2010

189. Modeling the Global Water Resource System in an Integrated Assessment Modeling Framework: IGSMWRS Strzepek et al. September 2010

190. Climatology and Trends in the Forcing of the Stratospheric Zonal-Mean Flow Monier and Weare January 2011

191. Climatology and Trends in the Forcing of the Stratospheric Ozone Transport Monier and Weare January 2011

192. The Impact of Border Carbon Adjustments under Alternative Producer Responses Winchester February 2011

193. What to Expect from Sectoral Trading: $A$ U.S.-China Example Gavard et al. February 2011

194. General Equilibrium, Electricity Generation Technologies and the Cost of Carbon Abatement Lanz and Rausch February 2011

195. A Method for Calculating Reference Evapotranspiration on Daily Time Scales Farmer et al. February 2011

196. Health Damages from Air Pollution in China Matus et al. March 2011

197. The Prospects for Coal-to-Liquid Conversion: A General Equilibrium Analysis Chen et al. May 2011

198. The Impact of Climate Policy on U.S. Aviation Winchester et al. May 2011

199. Future Yield Growth: What Evidence from Historical Data Gitiaux et al. May 2011

200. A Strategy for a Global Observing System for Verification of National Greenhouse Gas Emissions Prinn et al. June 2011

201. Russia's Natural Gas Export Potential up to 2050 Paltsev July 2011

202. Distributional Impacts of Carbon Pricing: A General Equilibrium Approach with Micro-Data for Households Rausch et al. July 2011
203. Global Aerosol Health Impacts: Quantifying Uncertainties Selin et al. August 201

204. Implementation of a Cloud Radiative Adjustment Method to Change the Climate Sensitivity of CAM3 Sokolov and Monier September 2011

205. Quantifying the Likelihood of Regional Climate Change: A Hybridized Approach Schlosser et al. October 2011

206. Process Modeling of Global Soil Nitrous Oxide Emissions Saikawa et al. October 2011

207. The Influence of Shale Gas on U.S. Energy and Environmental Policy Jacoby et al. November 2011

208. Influence of Air Quality Model Resolution on Uncertainty Associated with Health Impacts Thompson and Selin December 2011

209. Characterization of Wind Power Resource in the United States and its Intermittency Gunturu and Schlosser December 2011

210. Potential Direct and Indirect Effects of Global Cellulosic Biofuel Production on Greenhouse Gas Fluxes from Future Land-use Change Kicklighter et al. March 2012

211. Emissions Pricing to Stabilize Global Climate Bosetti et al. March 2012

212. Effects of Nitrogen Limitation on Hydrological Processes in CLM4-CN Lee \& Felzer March 2012

213. City-Size Distribution as a Function of Socio-economic Conditions: An Eclectic Approach to Down-scaling Global Population Nam \& Reilly March 2012

214. CliCrop: a Crop Water-Stress and Irrigation Demand Model for an Integrated Global Assessment Modeling Approach Fant et al. April 2012

215. The Role of China in Mitigating Climate Change Paltsev et al. April 2012

216. Applying Engineering and Fleet Detail to Represent Passenger Vehicle Transport in a Computable General Equilibrium Model Karplus et al. April 2012

217. Combining a New Vehicle Fuel Economy Standard with a Cap-and-Trade Policy: Energy and Economic Impact in the United States Karplus et al. April 2012

218. Permafrost, Lakes, and Climate-Warming Methane Feedback: What is the Worst We Can Expect? Gao et al. May 2012

219. Valuing Climate Impacts in Integrated Assessment Models: The MIT IGSM Reilly et al. May 2012

220. Leakage from Sub-national Climate Initiatives: The Case of California Caron et al. May 2012

221. Green Growth and the Efficient Use of Natural Resources Reilly June 2012

222. Modeling Water Withdrawal and Consumption for Electricity Generation in the United States Strzepek et al. June 2012

223. An Integrated Assessment Framework for Uncertainty Studies in Global and Regional Climate Change: The MIT IGSM Monier et al. June 2012

224. Cap-and-Trade Climate Policies with Price-Regulated Industries: How Costly are Free Allowances? Lanz and Rausch July 2012.

225. Distributional and Efficiency Impacts of Clean and Renewable Energy Standards for Electricity Rausch and Mowers July 2012. 